\title{
Histone modification dynamics as revealed by multicolor immunofluorescence-based single-cell analysis
}

\author{
Yoko Hayashi-Takanaka ${ }^{1,2, *}$, Yuto Kina ${ }^{3}$, Fumiaki Nakamura ${ }^{3}$, Leontine E. Becking ${ }^{4}$, Yoichi Nakao ${ }^{3}$, \\ Takahiro Nagase ${ }^{5}$, Naohito Nozaki ${ }^{6}$ and Hiroshi Kimura ${ }^{1,7, *}$
}

\begin{abstract}
Post-translational modifications on histones can be stable epigenetic marks or transient signals that can occur in response to internal and external stimuli. Levels of histone modifications fluctuate during the cell cycle and vary among different cell types. Here, we describe a simple system to monitor the levels of multiple histone modifications in single cells by multicolor immunofluorescence using directly labeled modification-specific antibodies. We analyzed histone $\mathrm{H} 3$ and $\mathrm{H} 4$ modifications during the cell cycle. Levels of active marks, such as acetylation and $\mathrm{H} 3 \mathrm{~K} 4$ methylation, were increased during the $S$ phase, in association with chromatin duplication. By contrast, levels of some repressive modifications gradually increased during G2 and the next G1 phases. We applied this method to validate the target modifications of various histone demethylases in cells using a transient overexpression system. In extracts of marine organisms, we also screened chemical compounds that affect histone modifications and identified psammaplin $A$, which was previously reported to inhibit histone deacetylases. Thus, the method presented here is a powerful and convenient tool for analyzing the changes in histone modifications.
\end{abstract}

KEY WORDS: Chemical biology, Chromatin, Epigenetics, Histone modification, Monoclonal antibody

\section{INTRODUCTION}

In eukaryotes, DNA is wrapped around eight histone proteins to form nucleosomes, which are the basic units of chromatin. Posttranslational modifications of histones play a crucial role in gene regulation by altering chromatin structure and/or recruiting reader proteins (Jenuwein and Allis, 2001; Kouzarides, 2007). Sitespecific acetylation and methylation of histone $\mathrm{H} 3$ lysine (H3K) residues are associated with gene activation and silencing

${ }^{1}$ Graduate School of Bioscience and Biotechnology, Tokyo Institute of Technology, 4259 Nagatsuta, Midori-ku, Yokohama 226-8501, Japan. ${ }^{2}$ Graduate School of Frontier Biosciences, Osaka University, 1-3, Yamadaoka, Suita 565-0871, Japan. ${ }^{3}$ Graduate School of Advanced Science and Engineering, Waseda University, 3-41 Okubo, Shinjuku-ku, Tokyo 169-8555, Japan. ${ }^{4}$ Marine Animal Ecology Group, Wageningen University \& Research, PO Box 338, Bode 36, $6700 \mathrm{AH}$ Wageningen, The Netherlands. ${ }^{5}$ Kazusa DNA Research Institute, Chiba 292-0818, Japan. ${ }^{6}$ Mab Institute Inc, 2070-11, Osegi, lida 395-0157, Japan. ${ }^{7}$ Cell Biology Center, Institute of Innovative Research, Tokyo Institute of Technology, 4259 Nagatsuta, Midori-ku, Yokohama 226-8503, Japan.

*Authors for correspondence (ythayashi@fbs.osaka-u.ac.jp; hkimura@bio.titech.ac.jp)

iD Y.H-T., 0000-0002-0556-6738; Y.K., 0000-0002-2174-3423; H.K., 0000-0003 0854-083X

This is an Open Access article distributed under the terms of the Creative Commons Attribution License (https://creativecommons.org/licenses/by/4.0), which permits unrestricted use

distribution and reproduction in any medium provided that the original work is properly attributed.

Handling Editor: Maria Carmo-Fonseca

Received 2 January 2020; Accepted 8 June 2020
(Lawrence et al., 2016) and their genome-wide distributions have been analyzed in various cell types (Kimura, 2013). Some modifications are stable epigenetic marks, whereas others turnover rapidly and/or exhibit dynamic changes in response to external and internal stimuli (McBrian et al., 2013; Niu et al., 2015) and during the cell cycle (Black et al., 2012). For example, H4 acetylation and $\mathrm{H} 3$ phosphorylation drastically increase during the $\mathrm{S}$ and $\mathrm{M}$ phases of the cell cycle, respectively (Chahal et al., 1980; Gurley et al., 1975). Recent analyses have also revealed that histone methylation states fluctuate during the cell cycle (Bar-Ziv et al., 2016; Petruk et al., 2013; Xu et al., 2012), possibly reflecting the balance between methylation and demethylation enzymes (Greer and Shi, 2012; Shmakova et al., 2014).

Histone modifications have traditionally been detected by radiolabeling and immunoassay using specific antibodies. Recently, mass spectrometry (MS) has emerged as a powerful method for comprehensively revealing multiple modifications in a single histone molecule, as well as their turnover rates (Zee et al., 2010a). These techniques require a homogenous population of a relatively large number of cells, often with cell cycle synchronization. By contrast, single-cell analysis based on flow cytometry and microscopy can be applied to a heterogeneous cell population, although the quality and accuracy of the results depend on the properties of the antibodies. A recent high-throughput microscopy-based single-cell assay has revealed differences in histone modifications between normal and cancer cells (Zane et al., 2017).

In this study, we report a simple multicolor immunofluorescence technique to reveal histone modifications in single cells using directly labeled modification-specific antibodies (Chandra et al., 2012; Hayashi-Takanaka et al., 2011, 2015; Kimura et al., 2008). With image analysis, we profiled levels of up to four histone modifications in single cells. We applied this method to the systematic analysis of the dynamic changes in histone modifications during the cell cycle and the targets of histone lysine demethylases (KDMs). Furthermore, we screened the extracts of marine organisms and identified a compound that inhibits histone deacetylase.

\section{RESULTS}

\section{Multicolor immunofluorescence-based single-cell analysis}

To analyze the global levels of multiple modifications in single cells, HeLa cells were grown on coverslips, fixed and immunolabeled with various antibodies directly conjugated to fluorescent dyes. Fig. 1 illustrates the scheme (Fig. 1A) and a typical example of the analysis (Fig. 1B-F) with antibodies directed against unmodified histone $\mathrm{H} 3$ at lysine 4 (H3K4un; Alexa Fluor 488), monomethylated histone $\mathrm{H} 4$ at $\mathrm{K} 20$ (H4K20me1; Cy3), and acetylated histone $\mathrm{H} 4$ at $\mathrm{K} 5$ (H4K5ac; Cy5). Cells were also stained with Hoechst 33342 to detect DNA. Fluorescence images were acquired using a wide-field fluorescence microscope with the standard filter sets (Fig. 1B), and the sum of intensities (average 

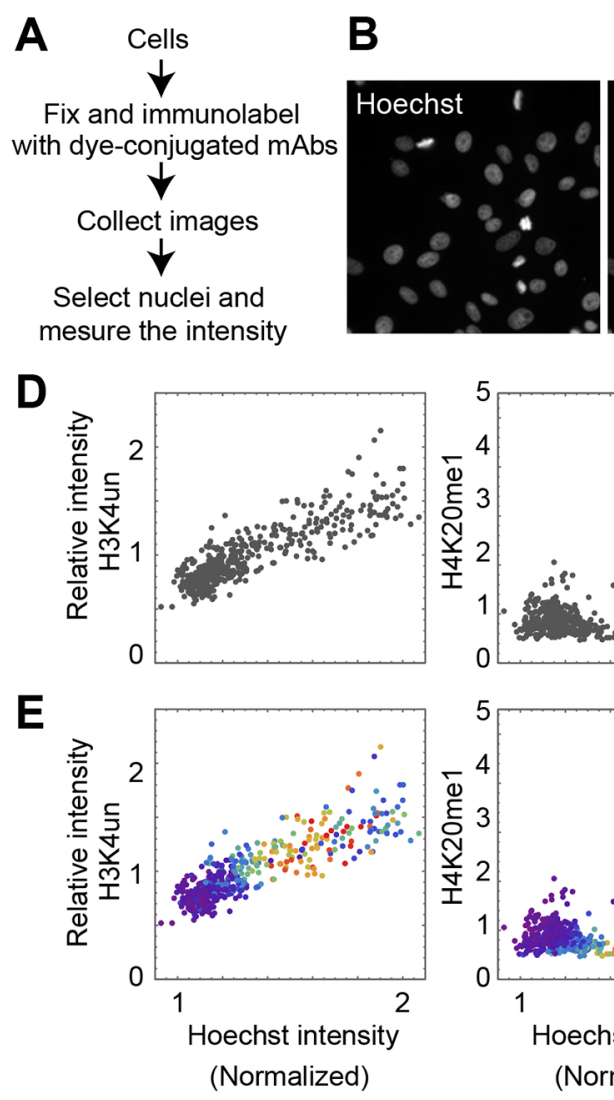
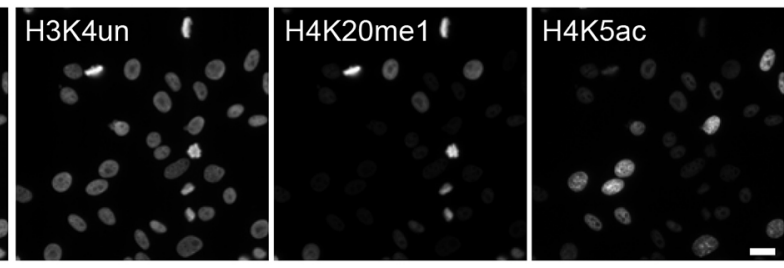

\section{C}

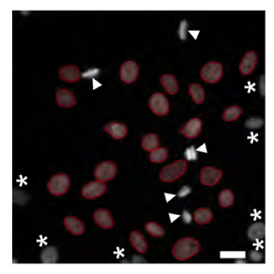

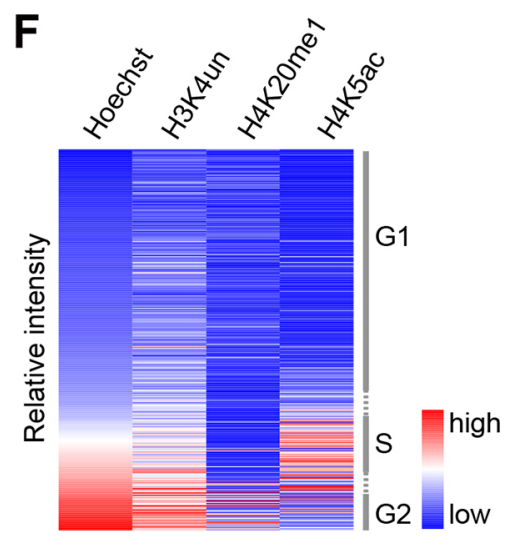

Fig. 1. Single-cell multicolor immunofluorescence analysis. (A) Experimental flow of the analysis. (B-F) HeLa cells were stained with Hoechst 33342 and antibodies specific for H3K4un (Alexa Fluor 488), H4K20me1 (Cy3) and H4K5ac (Cy5). (B) Microscopy images in four channels. (C) The areas of individual nuclei were determined by thresholding using Hoechst signals. Cells with incomplete nuclear shape (asterisks) were excluded from the analysis. Mitotic chromosomes with smaller areas than interphase nuclei (arrowheads) were also excluded from the analysis. (D) Typical two-dimensional graphs plotting relative intensity of histones against Hoechst intensity. The average intensity was set to 1 on the $y$-axis. (E) Typical three-dimensional graphs. Levels of replication marker H4K5ac are shown with the rainbow color code. (F) Typical heat maps. The relative intensities in single cells are color-coded and sorted using Hoechst signal intensity (lowest at the top and highest at the bottom). The positions of the cell cycle phase are indicated on the right. Cell numbers for D-F: 450 . Scale bars: $20 \mu \mathrm{m}$.

intensity number of pixels in the nuclear area) in each nucleus was measured (Fig. 1C). The partial nuclei at the edge of the field were removed because the whole nuclear area was used for determining the total signal intensity. To examine variations within a cell population, the relative signal intensity in each nucleus was obtained by normalization against the average of all nuclei.

Total signal intensities of various antibodies and the Hoechst dye shown in a dot plot (Fig. 1D) reveal the distribution of histone modification levels in different phases of the cell cycle, as judged by Hoechst total intensity. The level of H3K4un simply increased with cell cycle progression, which is consistent with the increase in the number of nucleosomes during DNA replication, as most of the H3K4 ( 90\%) was unmodified (Huang et al., 2015). Empirically, analysis of approximately 400-500 nuclei was usually sufficient to obtain feasible and reproducible results (Fig. S1A). The level of $\mathrm{H} 4 \mathrm{~K} 5 \mathrm{ac}$ modification was highest during the $\mathrm{S}$ phase, consistent with the diacetylation of histone $\mathrm{H} 4$ at $\mathrm{K} 5$ and $\mathrm{K} 12$ in a deposition complex (Allis et al., 1985; Chicoine et al., 1986; Sobel et al., 1995). The enrichment of H4K5ac in $\mathrm{S}$ phase cells was further confirmed by double staining using 5-ethynyl-2'-deoxyuridine (EdU), which was incorporated into the replicated DNA via pulselabeling immediately before cell fixation (Fig. S1B,C). Because H4K5ac could be a good S-phase marker, indicating H4K5ac levels in the color scale facilitated the identification of S-phase cells
(Fig. 1E). In contrast to H3K4un and $\mathrm{H} 4 \mathrm{~K} 5 \mathrm{ac}$, a drastic increase in H4K20me1 levels during G2 was observed (Fig. 1D,E). This was also consistent with previous reports demonstrating the fluctuation in H4K20me1 levels during the cell cycle, increasing at G2 and M phases (Pesavento et al., 2008; Rice et al., 2002; Sato et al., 2016). These data were consistent with profiles obtained using flow cytometry (Fig. S2A-C) and DNA staining with propidium iodide (PI), an intercalator without sequence specificity, instead of Hoechst binding to A/T-rich sequences (Fig. S2D,E). Therefore, the dot plots well represented the distribution of histone modifications during the cell cycle. However, we excluded mitotic cells from routine analysis for two reasons: First, mitotic chromosomes generally occupied smaller areas than occupied by nuclei at the nuclear focal plane, resulting in approximately 13\% lower total intensities (Fig. S2F). Second, most modification-specific antibodies used in this study are sensitive to the phosphorylation of neighboring serine/threonine residues that occurs during mitosis (Kimura et al., 2008; Hayashi-Takanaka et al., 2011; Kimura, 2013), which complicates data interpretation. Moreover, four new antibodies specific for histones unmodified on K9 and K27 (H3K9un and H3K27un) or modified by monomethylation (H3K27me1) or dimethylation (H3K27me2) of K27, did not bind to the target modifications when the next amino acid residues (S10 and S28) were phosphorylated (Fig. S3). The H3K27me1-specific 
antibody was also sensitive to R26 methylation and citrullination; however, these R26 modifications are not abundant (Guertin et al., 2014) and antagonize K27 methylation (Clancy et al., 2017), so their contribution would be minor.

To compare more than two modifications with the Hoechst signal, a heat map was used (Fig. 1F) in which each row corresponded to a single cell. When aligned in order of Hoechst intensity from the lowest (from the top to the middle and bottom rows in Fig. 1F, corresponding to G1, S and G2, respectively), the higher signals of H4K5ac and H4K20me1 appeared in the middle and bottom rows, respectively, consistent with cell cycle progress. Thus, once the immunostaining and intensity measurements are performed, an appropriate visualization method can be chosen, depending on the purpose of analysis.

\section{Evaluating the robustness of the assay system}

To evaluate the robustness of the assay, we examined the effects of antibody staining conditions using objective lenses with different numerical apertures (NAs). We first analyzed whether the antibody concentration is crucial for obtaining quantitative data. HeLa cells were fixed, permeabilized and incubated with serially diluted series of fluorescence-labeled antibodies $(0.25-4 \mu \mathrm{g} / \mathrm{ml})$. Immunofluorescence images were collected using the same exposure settings as those for quantitative analyses. Fluorescence intensities were lower in samples stained with lower antibody concentrations but the histone modification profiles were highly similar, regardless of the antibody concentration tested (Fig. S4). Next, we compared the profiles for single and double antibody staining to determine whether one antibody interferes with another via steric hindrance during multiple labeling (Fig. 2A). We chose combinations of two modifications that are relatively close and co-exist on a single histone molecule, such as H3K4un and H3K9me2 (Huang et al., 2015), H3K4me3 and H3K9ac (Kimura et al., 2008) and H3K27un and H3K36me3 (Yuan et al., 2011). For all tested combinations, the double labeling profiles were essentially the same as single labeling profiles (Fig. 2A), suggesting no or little effect of one antibody on the binding of another under the given conditions. This is probably because antibody binding was not at a saturated level (as seen in Fig. S4). Therefore, we conclude that the antibody concentration and combination are not crucial for the assay.

Furthermore, we investigated the suitability of objective lenses with different NAs for this assay (Fig. 2B,C). In principle, compared with a low NA objective lens, a high NA lens has superior optical resolution and brightness but is less tolerant to focal shifts, which can be a concern when many nuclei with slightly different focal planes are analyzed. When different objective lenses with NAs of 0.75-1.4 were compared, the intensity profiles were similar for lenses with NAs $0.75-1.25(20 \times$ to $60 \times)$, but the Hoechst intensities were distributed more broadly when a $100 \times$ NA 1.4 oil-immersion lens was used (Fig. 2B,C). These data suggest that a lens with the highest NA (1.4) may not be appropriate for this assay, even though the spatial distribution of individual modifications is better visualized. In contrast, the spatial resolution was poor with a $20 \times$ NA 0.75 lens (Fig. 2B). We also analyzed the effect of focal shifts on the quantified data using $40 \times$ NA 0.95 and $20 \times$ NA 0.75 objective lenses (Fig. 3). With the $40 \times$ NA 0.95 lens, a substantial difference in the intensity distribution was observed between the equatorial focal plane and a plane $1.5 \mu \mathrm{m}$ above the focus (Fig. 3A,B). The difference was small in a plane $0.75 \mu \mathrm{m}$ above the focus, suggesting that submicrometer focus shifts are tolerant for analysis using a $40 \times$ NA 0.95 lens. In contrast, using a $20 \times$ NA 0.75 lens, the intensity distributions of a plane $2.4 \mu \mathrm{m}$ above the focus were almost the same as those of the focal plane, which is consistent with the deeper focal depth of a low NA lens (Fig. 3C,D). Therefore, a $20 \times$ (NA 0.75) lens appears to be suitable for a high-throughput and robust analysis; however, a primary drawback is its poor resolution. Therefore, we routinely used a $40 \times$ dry NA 0.95 lens because the intranuclear distribution of individual modifications can be reasonably well visualized, submicrometer focal shifts are allowed and it is convenient to use without an immersion medium.

\section{Histone modifications during the cell cycle}

We first applied the multicolor immunofluorescence analysis to reevaluate changes in various histone modifications during the cell cycle (Fig. 4A). hTERT-RPE1 cells were fixed and stained with an Alexa Fluor 488-labeled modification-specific antibody, together with Cy5-labeled H4K5ac-specific antibody and Hoechst 33342. In dot plots, cells in the S phase were highlighted by higher H4K5ac levels using the rainbow color scale. To quantitatively compare the histone modification profiles with the DNA content (Hoechst) and S-phase enrichment (H4K5ac), Pearson correlation coefficients were calculated using three biologically independent experiments (Fig. 4B).

As a proof of concept, we first examined the levels of $\mathrm{H} 3 \mathrm{~K} 4 \mathrm{un}$ and H4K12ac. As mentioned above, we expected high correlations between H3K4un and DNA content and between H4K12ac and H4K5ac. Indeed, H3K4un showed a strong correlation with the Hoechst signal (correlation factor, 0.95; Fig. 4B). The distribution profile of H4K12ac was similar to that of H4K5ac (Fig. 4A), with a high correlation (correlation factor, 0.85; Fig. 4B), consistent with their coexistence in newly assembled chromatin (Allis et al., 1985; Chicoine et al., 1986; Sobel et al., 1995). These data indicate that the analytical method presented here can be used to evaluate histone modification profiles during the cell cycle.

To overview the characteristics of individual modifications (Fig. 4A,B), we plotted their correlation with Hoechst 33342 and H4K5ac signals (Fig. 4C). Based on the correlations with H4K5ac, we classified histone modifications into three groups. The first group, showing high correlations with $\mathrm{H} 4 \mathrm{~K} 5 \mathrm{ac}(>0.6)$, contained unmodified H3K9 and H3K27 (H3K9un and H3K27un) and all histone acetylations, except H4K16ac. These modifications also showed high correlations with Hoechst signal ( $>0.7)$. In single-cell dot plots (Fig. 4A), their signal intensities were clearly increased in S-phase cells. These data suggest that newly assembled histones are acetylated soon after DNA replication. The higher levels of these modifications during $S$ phase than during $\mathrm{G} 2$ phase could be correlated with chromatin decondensation during or after DNA replication, as reported previously (Li et al., 1998). Levels of H3K9un and H3K27un also increased during the S phase, thus reflecting assembly of the unmodified form of $\mathrm{H} 3$ (Jasencakova et al., 2010). In contrast to H3K4un, the levels of H3K9un and H3K27un decreased during G2 phase, being reciprocal to the increase in the abundant methylation of lysine residues (e.g. H3K9me2 and H3K27me1, both occupying 36\% of the H3) (Huang et al., 2015) from late S to G2 phase.

The second group, showing low to modest correlations with H4K5ac (0.25-0.6), contained all forms of H3K4, together with H3K9me1 and H3K27me2 (Fig. 4C). These H3K4 modifications also showed high correlations with Hoechst signal $(>0.75)$, particularly $\mathrm{H} 3 \mathrm{~K} 4 \mathrm{me} 2(0.94)$ and $\mathrm{H} 3 \mathrm{~K} 4 \mathrm{me} 3$ (0.90). These data suggest that methylations of $\mathrm{H} 3 \mathrm{~K} 4$, which are associated with transcriptionally active chromatin (Bernstein et al., 2005; Kim et al., 2005; Roh et al., 2005), occur soon after DNA replication during the early $\mathrm{S}$ phase, consistent with the relatively rapid turnover rate of these methylations (Reverón-Gómez et al., 2018). 
A

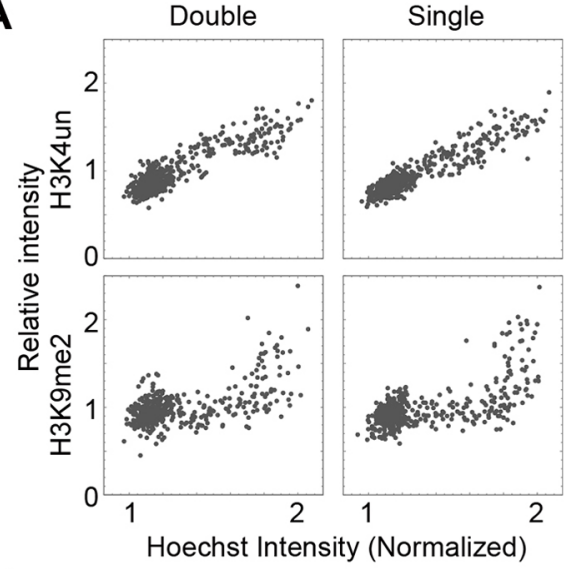

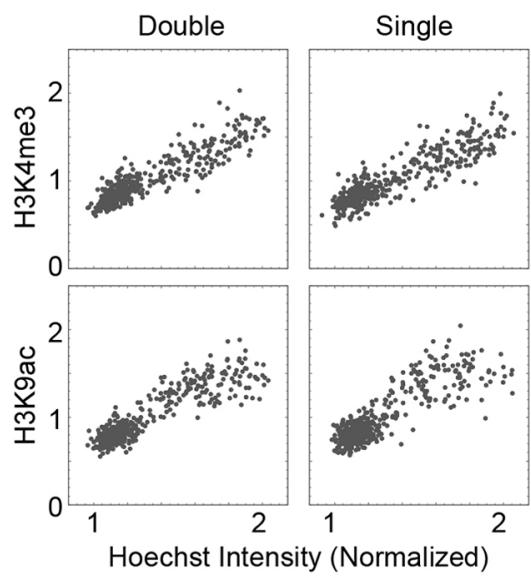

C H3K4un

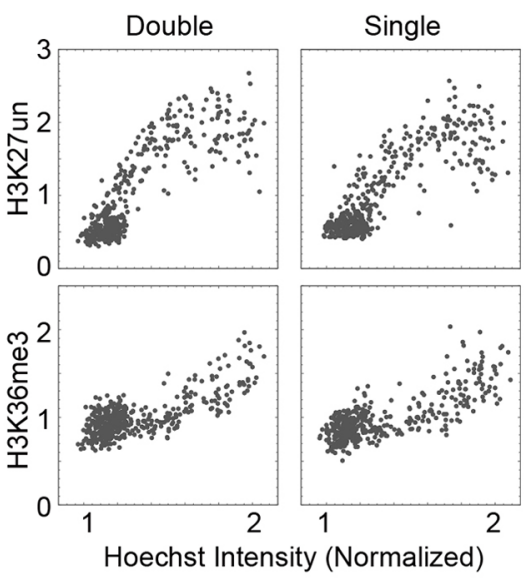

H4K20me1

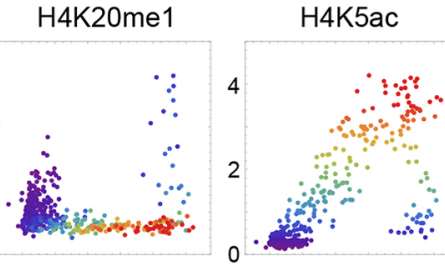

0

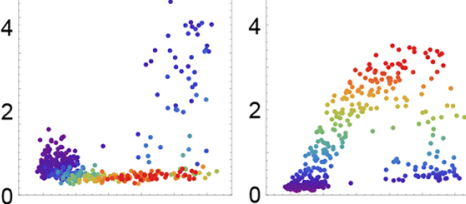

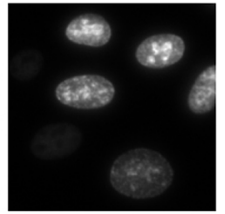
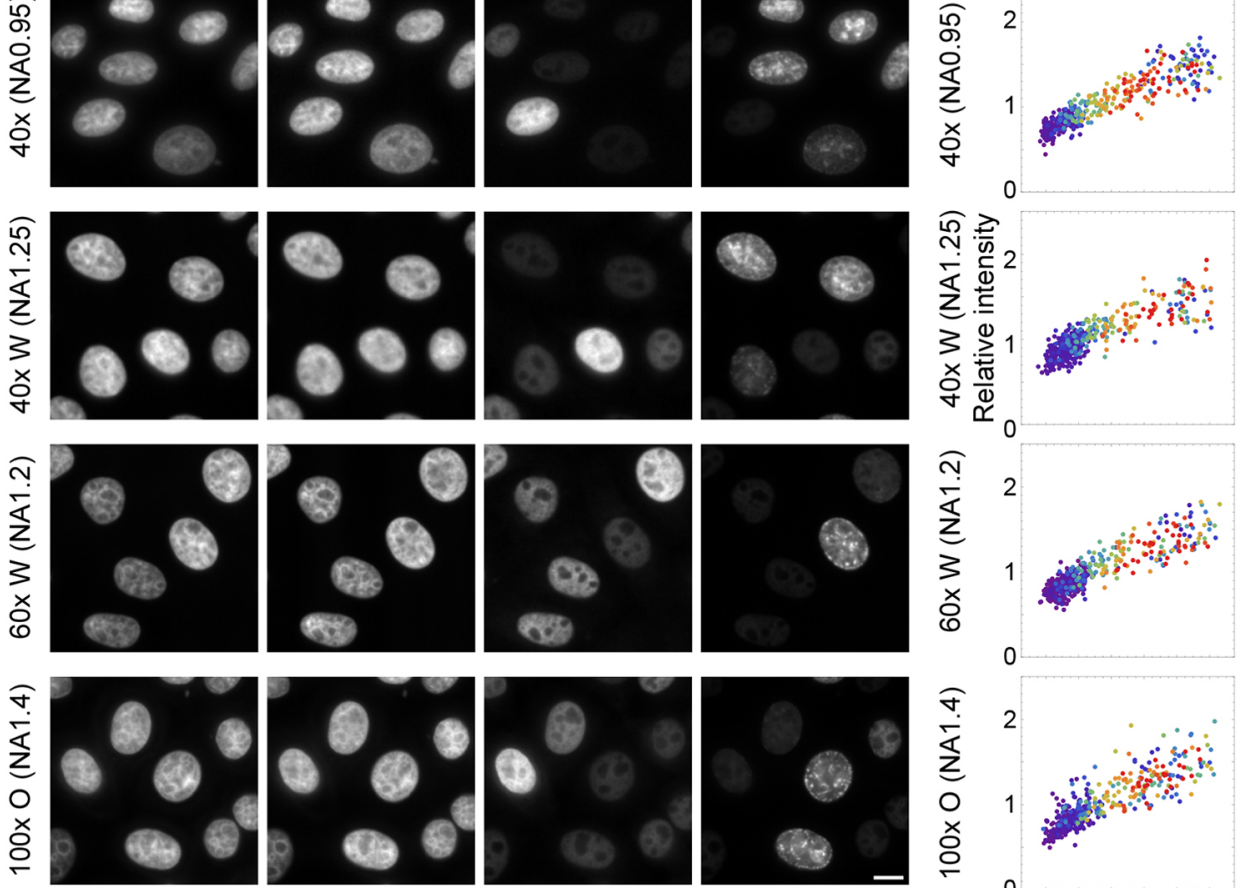

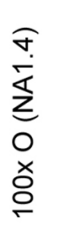
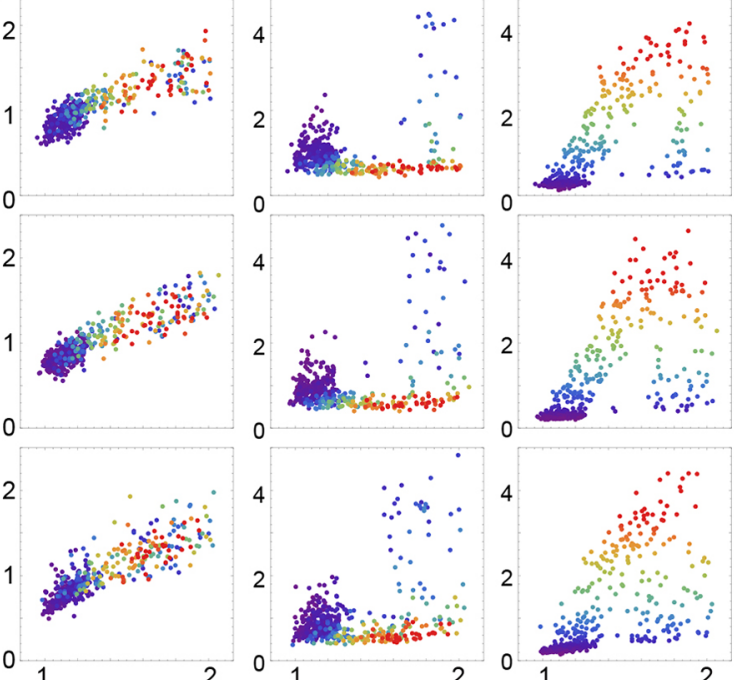

Hoechst intensity (Normalized)

Fig. 2. Effects of antibody staining and imaging conditions using different objective lenses. (A) Comparison of single and double antibody staining. Fixed and permeabilized HeLa cells were stained with a single antibody or a pair of antibodies, using a combination of $\mathrm{H} 3 \mathrm{~K} 4 \mathrm{un}$ and $\mathrm{H} 3 \mathrm{~K} 9 \mathrm{me} 2, \mathrm{H} 3 \mathrm{~K} 4 \mathrm{me} 3$ and $\mathrm{H} 3 \mathrm{~K} 9 \mathrm{ac}$, or H3K27un and H3K36me3. The profiles of histones and Hoechst intensities are shown. Cell numbers: 420 . (B,C) Effects of the numerical aperture and magnification of the objective lens on the intensity profiles. Fixed and permeabilized HeLa cells were stained using Hoechst 33342 and antibodies specific for H3K4un (Alexa Fluor 488), H4K20me1 (Cy3) and H4K5ac (Cy5). Images were collected using five different lenses: 20× (dry, NA 0.75), 40× (dry, NA 0.95), 40× (water-immersion, NA 1.25), 60× (water-immersion, NA 1.2), and 100× (oil-immersion, NA 1.4). Typical images are shown in B. Signal intensities of histones plotted against Hoechst intensity and H4K5ac levels are shown in C, with the rainbow color code as in Fig. 1E. Cell numbers: 450 . Scale bar: $10 \mu \mathrm{m}$.

Because H3K9me1 is also enriched in the gene body of transcribed genes, chromatin containing this modification is likely to be replicated during early $\mathrm{S}$ phase, and it can be restored during $\mathrm{S}$ phase. This methylation is mediated through the G9a/GLP complex, which is also a methyltransferase responsible for $\mathrm{H} 3 \mathrm{~K} 9 \mathrm{me} 2$ that is restored after the S phase (see below) (Alabert et al., 2015; Lin et al., 2016). H3K27me2 is an abundant modification, occupying 34\% of H3 (Huang et al., 2015), and the polycomb repressive complex 2 acts as a methyltransferase for this modification as well as for H3K27me3 (Harutyunyan et al., 2019). The H3K27me2-containing 

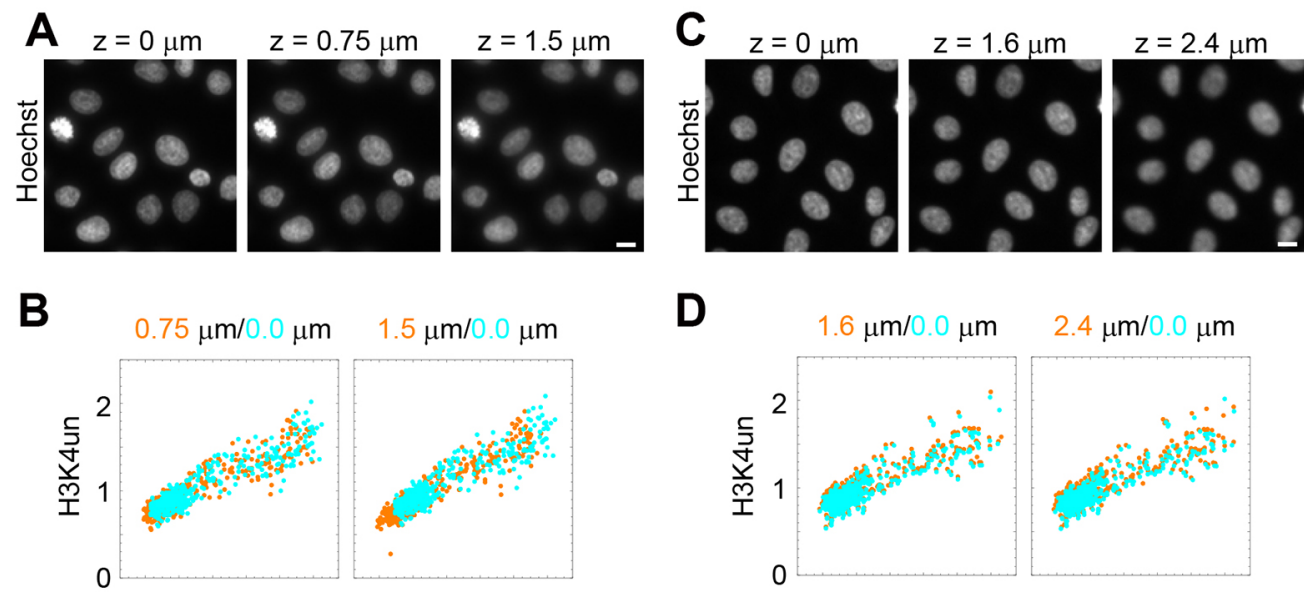

D
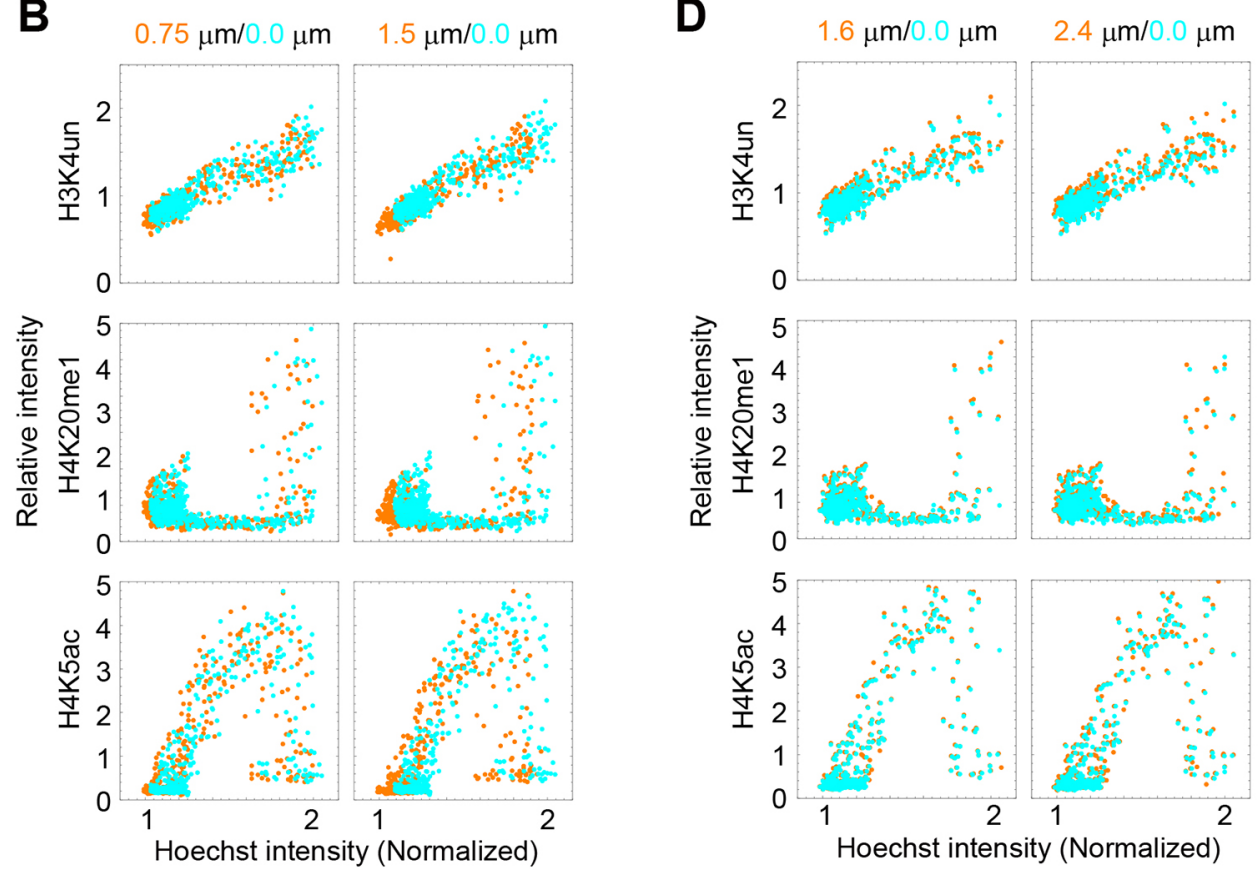
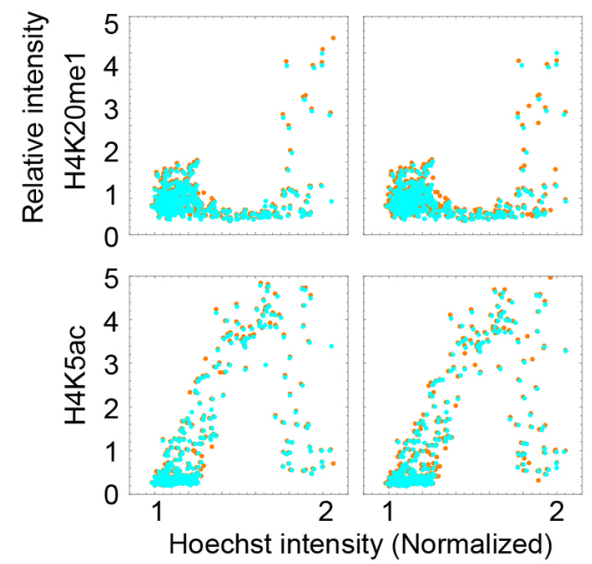

Fig. 3. Effects of focal shifts on intensity profiling. Fixed and

permeabilized HeLa cells were stained with Hoechst 33342 and antibodies specific for H3K4un (Alexa Fluor 488), H4K20me1 (Сy3) and H4K5ac (Cy5).

$(A, C)$ Fluorescence images were collected in a z-stack using an NA 0.95 $40 \times$ objective lens with $0.25 \mu \mathrm{m}$ intervals (A) and an NA $0.7520 \times$ lens with $0.4 \mu \mathrm{m}$ intervals (C). Hoechst images were taken at different planes in $\mathrm{A}$ and C. Distances from the focal plane are indicated. (B,D) Intensities in the different focal planes were measured, normalized and plotted. The intensities in the focal and another plane are indicated in cyan and orange, respectively. Cell numbers: 450 . Scale bars: $10 \mu \mathrm{m}$. chromatin might replicate earlier than $\mathrm{H} 3 \mathrm{~K} 27 \mathrm{me} 3$ for earlier restoration.

The third group, showing little or anti-correlation with H4K5ac $(<0.2)$, contained repressive marks and $\mathrm{H} 3 \mathrm{~K} 36$ methylation. In this group, correlations of the Hoechst signal with the constitutive (H3K9me3) and facultative (H3K27me3) heterochromatin marks were also low. Levels of modification decreased during the middleto-late $\mathrm{S}$ phase and increased during G2 phase and the next G1 phase (Fig. 4A). In addition, levels of these modifications showed a broad distribution in $\mathrm{G} 1$ cells. This suggests that these modifications were not restored during the $\mathrm{S}$ and $\mathrm{G} 2$ phases within the same cell cycle and continued increasing during the next G1 phase. These observations are consistent with reports showing a transient decrease in the levels of these modifications during $\mathrm{S}$ phase, and their delayed restoration in the next cell cycle (Alabert et al., 2015; Reverón-Gómez et al., 2018; Xu et al., 2012; Zee et al., 2012). The level of H3K9me2 did not change much during most of the S phase and increased during late $\mathrm{S}$ and G2 phases (Fig. 4A), showing a modest correlation with the Hoechst signal (0.45), unlike H3K9me1. As mentioned above, the different restoration timing might reflect the different replication timing of $\mathrm{H} 3 \mathrm{~K} 9 \mathrm{me} 1-$ and $\mathrm{H} 3 \mathrm{~K} 9 \mathrm{me} 2$-rich chromatin and/or a stepwise progression in the order of mono- and dimethylation mediated by the G9a/GLP complex. The restoration of $\mathrm{H} 3 \mathrm{~K} 9 \mathrm{me} 2$ might continue throughout the next G1 phase (Fukuda et al., 2019).

Additional methylation marks, including H3K36me2, H3K36me3 and H3K27me1, behaved similarly to H3K9me2, but with slightly higher correlations with the Hoechst signal $(>0.6)$. The delay in replication could partly explain the profile, although the mechanism remains unknown. H3K36me2 and
H3K36me3 localized broadly to euchromatin and the gene body, respectively (Li et al., 2019; Zee et al., 2010b), and the replication timing of chromatin that harbors these modifications might not be as early as that of H3K4-associated chromatin. Because H3K27 is reportedly methylated (H3K27me1) in combination with $\mathrm{H} 3 \mathrm{~K} 36$ (Zheng et al., 2016), its dynamics could be similar to H3K36 methylation.

Unlike other acetylation marks, H4K16ac belonged to the third group, showing a lower correlation with H4K5ac (0.20). The level of H4K16ac increased throughout the S and G2 phases. Because $\mathrm{H} 4 \mathrm{~K} 16 \mathrm{ac}$ is an abundant acetylation mark ( $30-40 \%$ of total H4 in HeLa cells) (Smith et al., 2003), its full restoration might require more time than other acetylation marks. The replication-uncoupled acetylation mechanism might also help regulate this aging-related acetylation (Dang et al., 2009). The abundance of H4K20me2 and H4K20me3 was gradually restored during late $\mathrm{S}$ phase to the next G1 phase, which is consistent with previous data (Pesavento et al., 2008; Yamamoto et al., 2015). Overall, the cell cycle analysis data based on multicolor immunofluorescence are in good agreement with previous findings, thus confirming the validity of this method.

\section{Targets of lysine demethylases}

We applied the assay to analyze systematically the cellular targets of lysine demethylases (KDMs) by transiently expressing HaloTagfusion proteins in 293T cells (Figs 5, 6). Cells grown on coverslips were transfected and then fixed the next day for staining with fluorescently (Alexa Fluor 488, Cy3, or Cy5) labeled antibodies directed against mono-, di- and trimethylated forms on the same lysine residue. The HaloTag-KDM was detected by HaloTagspecific rabbit polyclonal antibody with Alexa Fluor 750-labeled 
A

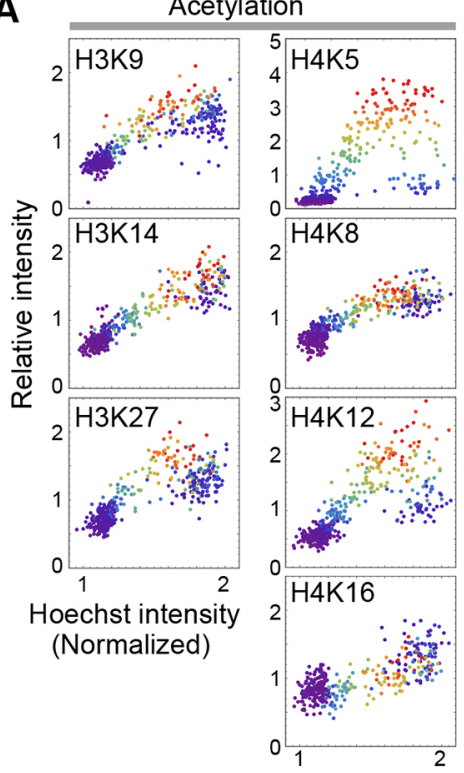

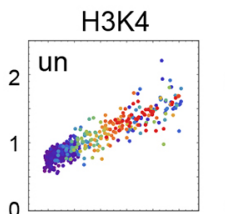
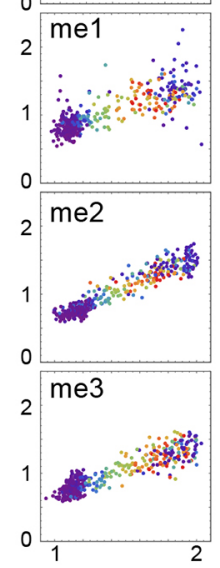
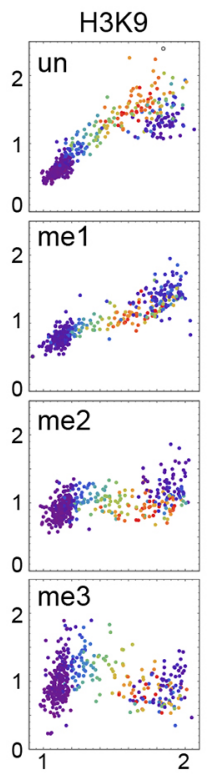

0

c

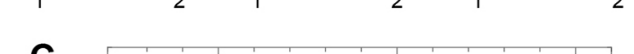

B

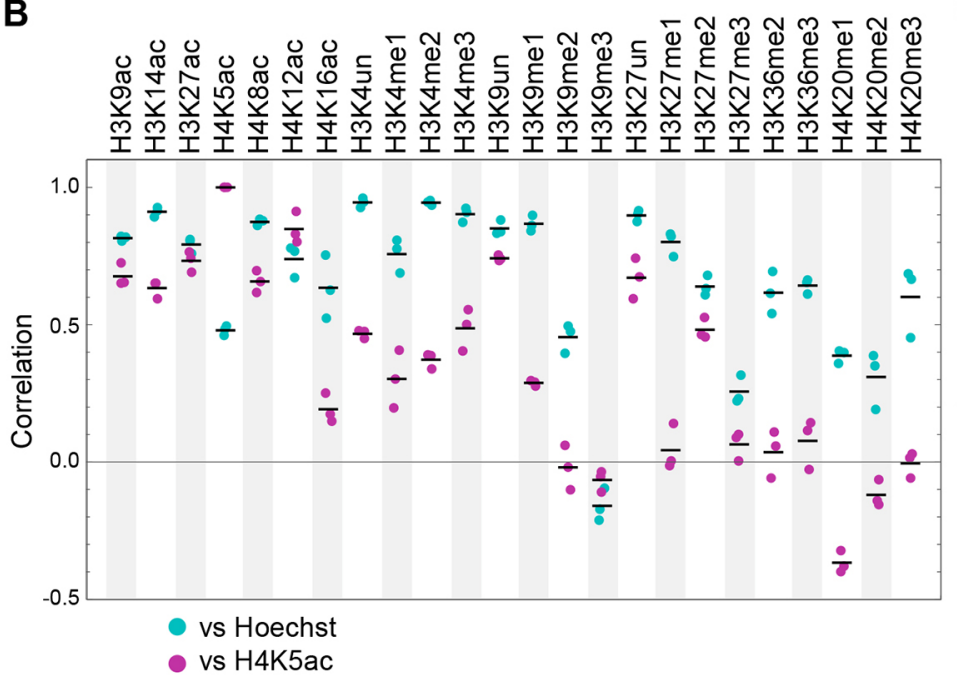

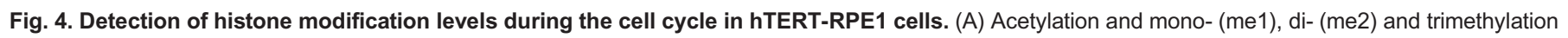
(me3) of histones $\mathrm{H} 3$ and $\mathrm{H} 4$ during the cell cycle; un, unmodified. Cell numbers: 450. (B) Correlation between target modification and Hoechst or H4K5ac signals.

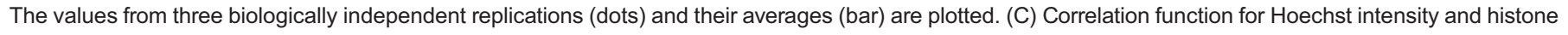
modification, based on B, plotted in two dimensions.

anti-rabbit IgG. Fig. 5A illustrates a typical example of cells that were transfected with a HaloTag-KDM4D expression vector and then stained with antibodies specific for H3K9me1 (Alexa Fluor 488), H3K9me2 (Cy3), H3K9me3 (Cy5) and HaloTag (Alexa Fluor 750), together with Hoechst 33342. The HaloTag-positive cells showed more intense signals for $\mathrm{H} 3 \mathrm{~K} 9 \mathrm{me} 1$ and less intense signals for $\mathrm{H} 3 \mathrm{~K} 9 \mathrm{me} 2$ and $\mathrm{H} 3 \mathrm{~K} 9 \mathrm{me} 3$ (Fig. 5A, arrows), indicating that HaloTag-KDM4D removed methyl groups from H3K9me2 and H3K9me3, converting them to H3K9me1.

After quantifying the fluorescence signals of individual nuclei, the relative intensities were expressed as a heat map, which was aligned in order of the HaloTag level for 400 randomly selected cells (Fig. 5B; left columns for each methylation site). Because many cells did not express HaloTag-KDM or showed a low level of expression, the top 50 cells showing higher expression levels were zoomed-in (Fig. 5B; right columns). The decreased levels of methylation are shown in blue. To evaluate quantitatively the effect of KDM expression on individual histone modifications, Pearson correlations were calculated; the results of two independent experiments are shown in Fig. 6.

H3K4 was demethylated by KDM5 family members (Greer and Shi, 2012). Expression of KDM5A and KDM5B reduced the levels of all three methylation patterns (mono-, di- and tri-), as reported previously (Christensen et al., 2007), and KDM5C showed weak activity. We then stained transfected cells with H3K4un together with $\mathrm{H} 3 \mathrm{~K} 4 \mathrm{me} 1$ and $\mathrm{H} 3 \mathrm{~K} 4 \mathrm{me} 3$ in an attempt to see whether the increased level of H3K4un could be reciprocally observed in cells that lost methylation at $\mathrm{H} 3 \mathrm{~K} 4$ (Fig. 5C). In cells expressing HaloTag-KDM5A and HaloTag-KDM5B, the levels of H3K4un were moderately high but not the highest, possibly because methylated H3K4 occupies only $\sim 13 \%$ of the H3 (Huang et al., 2015); therefore, only a small increase in the level of H3K4un would be expected even if all of the methylated fraction changed to the unmodified state. 
A
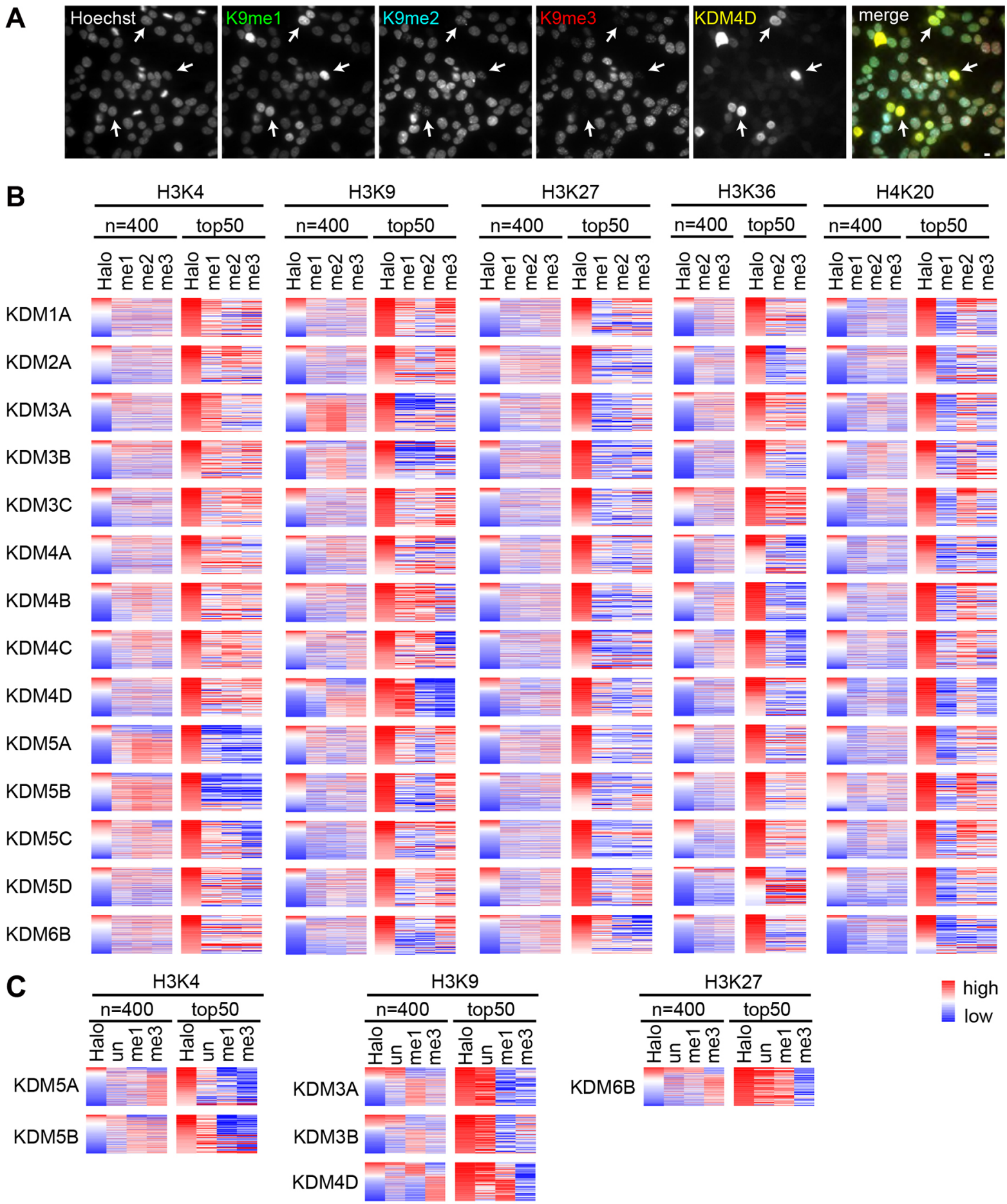

\begin{tabular}{|c|c|}
\hline \multicolumn{2}{|c|}{ H3К36 } \\
\hline$n=400$ & top50 \\
\hline 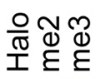 & 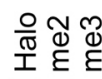 \\
\hline
\end{tabular}

\begin{tabular}{|c|c|}
\hline \multicolumn{2}{|c|}{$\mathrm{H} 4 \mathrm{~K} 20$} \\
\hline$n=400$ & top50 \\
\hline & 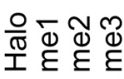 \\
\hline
\end{tabular}
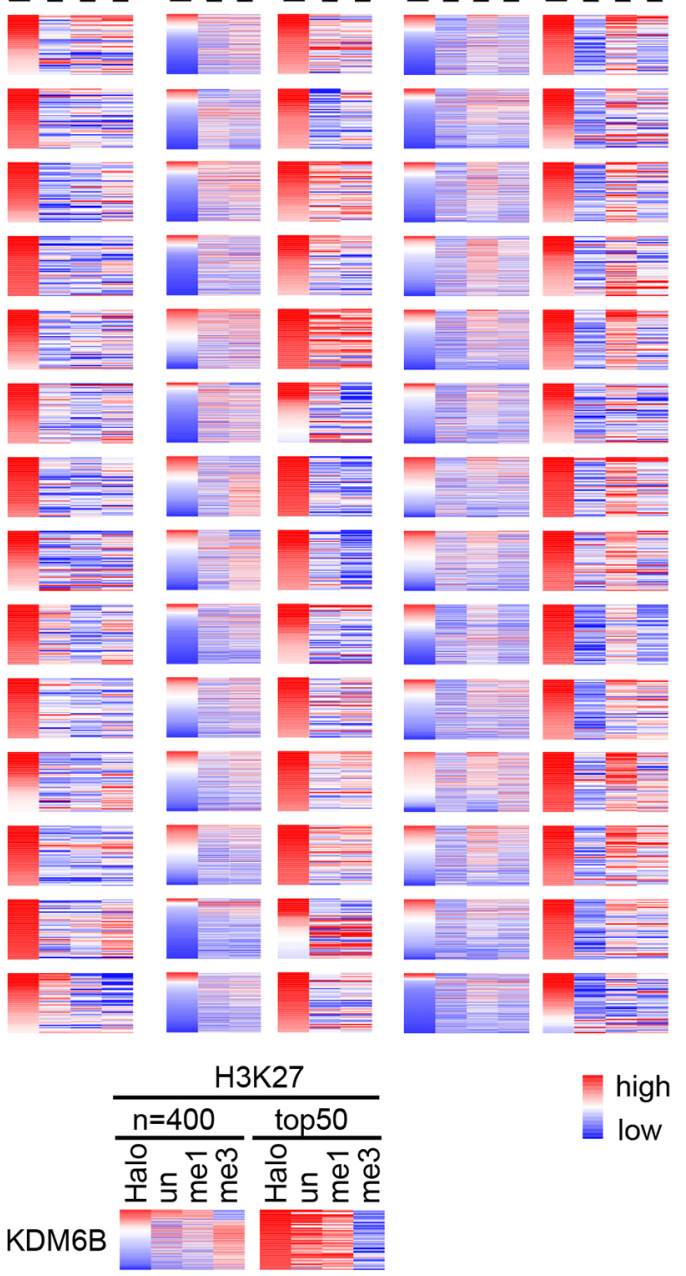

high

low

Fig. 5. Effect of histone demethylase on histone modifications in the 293T cells. (A) Images of KDM-overexpressing cells. 293T cells were transiently transfected with various HaloTag-KDM expression vectors. After fixation, the cells were stained with Hoechst 33342, anti-HaloTag antibody and three anti-histone modification-specific antibodies. The example images are of cells that overexpressed KDM4D and were stained with anti-H3K9me1, H3K9me2, H3K9me3 and HaloTag antibodies. (B) Heat maps showing the three methylation levels (mono-, di-, and tri-) associated with HaloTag-KDM overexpression and sorted by HaloTag expression. The results of both whole cells ( 400 cells) and the top 50 cells expressing higher levels of HaloTag are shown. The decreased levels of methylation are shown in blue. (C) Effects of HaloTag-KDM expression on the levels of unmodified, mono- and trimethylated histone lysine residues. Scale bar: $10 \mu \mathrm{m}$.

H3K9 was demethylated by various KDM families, including KDM3 and KDM4. The KDM3A and KDM3B enzymes preferentially reduced the levels of $\mathrm{H} 3 \mathrm{~K} 9 \mathrm{me} 1$ and $\mathrm{H} 3 \mathrm{~K} 9 \mathrm{me} 2$ more than that of $\mathrm{H} 3 \mathrm{~K} 9 \mathrm{me} 3$ (Fig. 5B, Fig. 6). An increase in the level of H3K9un was reciprocally observed (Fig. 5C), consistent with the abundance of methylation ( $\sim 20 \%$ and $\sim 35 \%$ for mono- and dimethylation, respectively) similarly to and higher than that without methylation $(\sim 21 \%)$ (Huang et al., 2015). Among the KDM4 family members, KDM4D demethylated both H3K9me2 and $\mathrm{H} 3 \mathrm{~K} 9 \mathrm{me} 3$ to yield $\mathrm{H} 3 \mathrm{~K} 9$ un and H3K9me1 (Fig. 5B,C). 


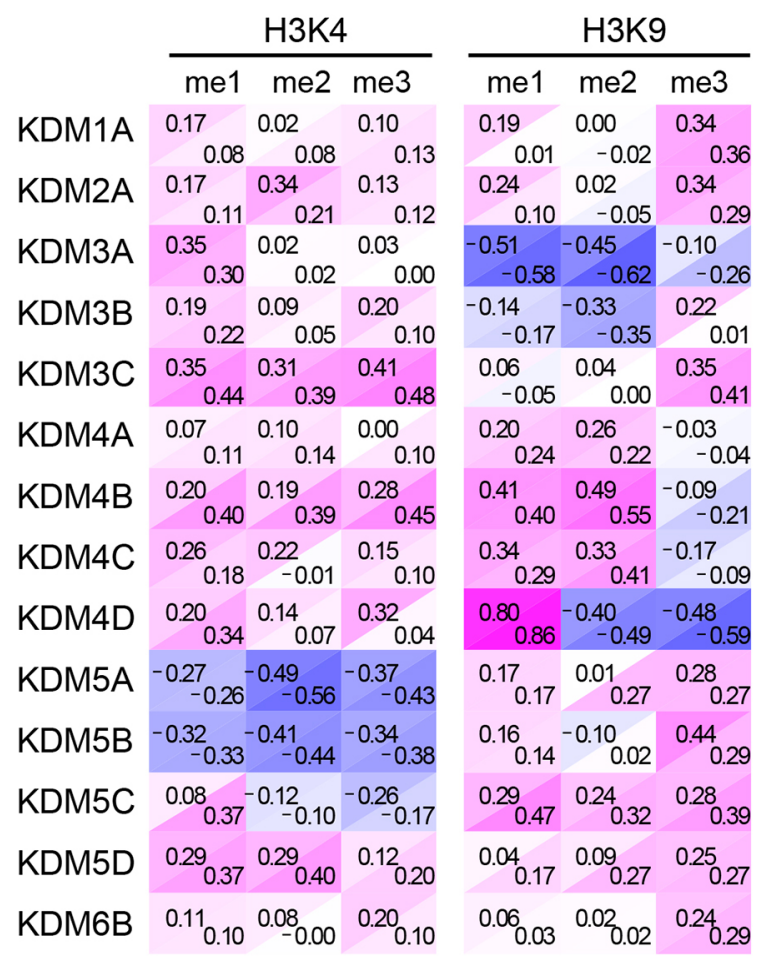

\begin{tabular}{|c|c|c|c|c|}
\hline \multicolumn{3}{|c|}{ H3К27 } & \multicolumn{2}{|c|}{ H3К36 } \\
\hline me1 & me2 & e3 & e2 & ne3 \\
\hline $\begin{array}{l}0.05 \\
-0.08\end{array}$ & $\begin{array}{l}0.12 \\
-0.10\end{array}$ & $-c$ & $\begin{array}{l}.10 \\
-0.01\end{array}$ & 0.0 \\
\hline 0.0 & -0.10 & 017 & & \\
\hline .01 & 0.07 & 0 & -0.44 & -0.20 \\
\hline $\begin{array}{l}0.14 \\
-0.28\end{array}$ & $\begin{array}{l}-0.07 \\
-0.21\end{array}$ & $\begin{array}{r}-0.03 \\
-0\end{array}$ & $\begin{array}{l}0.25 \\
0.05\end{array}$ & $\begin{array}{l}0.14 \\
0.02\end{array}$ \\
\hline $\begin{array}{l}0.21 \\
-0.13\end{array}$ & $\begin{array}{c}-0.17 \\
-0.07\end{array}$ & $\begin{array}{r}-0.16 \\
-6\end{array}$ & $\begin{array}{l}0.14 \\
0.12\end{array}$ & $\begin{array}{l}0.05 \\
0.05\end{array}$ \\
\hline $\begin{array}{l}0.09 \\
-0.08\end{array}$ & $\begin{array}{c}-0.00 \\
0.03\end{array}$ & $\begin{array}{c}0.04 \\
0.08\end{array}$ & $\begin{array}{l}0.37 \\
0.29\end{array}$ & $\begin{array}{l}0.27 \\
0.18\end{array}$ \\
\hline $\begin{array}{l}-0.02 \\
-0.05\end{array}$ & $\begin{array}{l}0.03 \\
-0.07\end{array}$ & $\begin{array}{l}-0.04 \\
-0.09\end{array}$ & $\begin{array}{l}0.12 \\
0.08\end{array}$ & $\begin{array}{r}-0.22 \\
-0.12\end{array}$ \\
\hline $\begin{array}{l}0.06 \\
-0.03\end{array}$ & $\begin{array}{c}-0.10 \\
0.12\end{array}$ & $\begin{array}{l}-0.08 \\
0.12\end{array}$ & $\begin{array}{r}-0.05 \\
0.03\end{array}$ & $\begin{array}{r}-0.26 \\
-0.31\end{array}$ \\
\hline $\begin{array}{l}-0.09 \\
-0.11\end{array}$ & $\begin{array}{l}-0.04 \\
-0.01\end{array}$ & $\begin{array}{r}-0.00 \\
0.09\end{array}$ & $\begin{array}{l}0.01 \\
0.07\end{array}$ & $\begin{array}{r}-0.29 \\
-0.28\end{array}$ \\
\hline $\begin{array}{r}0.18 \\
0.30\end{array}$ & $\begin{array}{r}-0.14 \\
0.01\end{array}$ & $\begin{array}{c}-0.09 \\
-0.06\end{array}$ & $\begin{array}{l}0.19 \\
0.06\end{array}$ & $\begin{array}{r}0.26 \\
0.05\end{array}$ \\
\hline $\begin{array}{l}-0.09 \\
-0.04\end{array}$ & $\begin{array}{r}-0.10 \\
0.09\end{array}$ & $\begin{array}{r}-0.17 \\
-0\end{array}$ & $\begin{array}{r}0.04 \\
0.21\end{array}$ & $\begin{array}{c}0.08 \\
0.11\end{array}$ \\
\hline $\begin{array}{l}0.00 \\
0.13\end{array}$ & $\begin{array}{l}-0.02 \\
-0.01\end{array}$ & $\begin{array}{r}-0.01 \\
0 .\end{array}$ & $\begin{array}{l}0.18 \\
0.30\end{array}$ & $\begin{array}{l}0.20 \\
0.28\end{array}$ \\
\hline-0.09 & - & $\begin{array}{r}-0.04 \\
-0 .\end{array}$ & $\begin{array}{l}0.25 \\
0.38\end{array}$ & 0.33 \\
\hline-0.06 & -0.040 .13 & $\begin{array}{l}0.01 \\
0.17\end{array}$ & $\begin{array}{l}0.11 \\
0.27\end{array}$ & $\begin{array}{c}0.09 \\
0.3\end{array}$ \\
\hline 0.33 & & & 0.10 & 0.07 \\
\hline
\end{tabular}

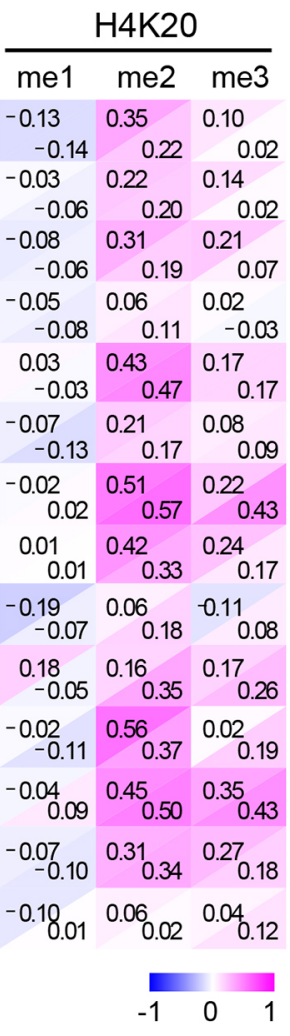

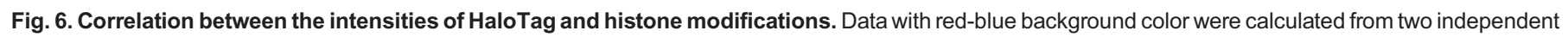
experiments, based on Fig. 5B.

H3K27me3 was demethylated by KDM6B overexpression (Fig. 5B, Fig. 6), consistent with previous reports (Agger et al., 2007; Chandra et al., 2012; Hong et al., 2007; Lan et al., 2007; Xiang et al., 2007). Levels of H3K27un and H3K27me1 were reciprocally increased in cells expressing KDM6B (Fig. 5B,C). H3K36 was demethylated by KDM2A and KDM4 family members. KDM2A showed preference for H3K36me2 over H3K36me3, whereas KDM4 showed the opposite trend (Hillringhaus et al., 2011; Tsukada et al., 2006). Methylation levels of H4K20 did not show a significant decrease with the KDMs used in this study. Overall, these results confirmed previous observations, further supporting the reliability of the assay system.

\section{Screening of marine organism extracts}

We then applied the method for screening bioactive compounds from marine organisms (Hayashi-Takanaka et al., 2019). MDAMB-231 breast cancer cells were grown in 96-well glass-bottom plates and cultured for 18-24 h with organic compounds extracted from marine organisms (Fig. 7A). The cells were then fixed and incubated with Hoechst 33342 and various histone modificationspecific antibodies (Fig. S5). Among 3750 extracts tested, the hydrophobic extract (S09420) prepared from a marine sponge Aplysilla sp. collected at Chuuk, Federated States of Micronesia, markedly increased the levels of H3K9ac (Fig. 7B) and other acetylations (Fig. S5). To purify the compound responsible for the increase in $\mathrm{H} 3 \mathrm{~K} 9 \mathrm{ac}$ level, the extract was fractionated by solvent partitioning and column chromatography (Fig. 7C). Levels of $\mathrm{H} 3 \mathrm{~K} 9 \mathrm{ac}$ and $\mathrm{H} 3 \mathrm{~K} 27 \mathrm{ac}$ were increased in cells treated with fraction 3 and fraction 8 through a $\mathrm{C}_{18}$ HPLC column (Fig. 7D). MS and NMR spectrometry (Fig. 7E; Fig. S6) revealed that both fractions contained psammaplin A, which was isolated from marine sponges including Psammaplysilla sp. (Arabshahi and Schmitz, 1987; Quiñoà and Crews, 1987; Rodriguez et al., 1987). Psammaplin A has been reported to inhibit the activity of DNA topoisomerase (Jiang et al., 2004), gyrase (Tabudravu et al., 2002), histone deacetylase (HDAC) and DNA methyltransferase in vitro (Piña et al., 2003).

We next compared the effects of psammaplin A on $\mathrm{H} 3$ and $\mathrm{H} 4$ acetylation with the commonly used HDAC inhibitors, trichostatin A (TSA) and suberoylanilide hydroxamic acid (SAHA) (Fig. 7F). Cells were incubated in serial dilutions of these compounds $(0,1$, 10,100 and $1000 \mathrm{nM}$ ) for $4 \mathrm{~h}$ and then fixed and stained with acetylation-specific antibodies. After measuring the fluorescence intensity in each nucleus in different samples, the values were normalized relative to the average of the untreated samples. The results showed that in the presence of psammaplin $\mathrm{A}$, the acetylation levels of H3K9, H3K14, H3K27, H4K5, H4K8 and H4K12 were slightly increased at $100 \mathrm{nM}$ and greatly increased at $1000 \mathrm{nM}$, similar to SAHA. The potency of TSA appeared to be roughly tenfold higher than that of psammaplin A and SAHA, and was effective at $10 \mathrm{nM}$. These results suggest that psammaplin A has a broad inhibitory spectrum, like TSA and SAHA.

\section{DISCUSSION}

Here, we present a simple method for conducting a systematic analysis of the global level of multiple histone modifications in single cells. Using antibodies that were directly labeled with different fluorescent dyes, multiple modifications (mono-, di-, and trimethylation on a specific residue) were visualized using a widefield fluorescence microscope. Image analysis with quantitation revealed the relative abundance of these modifications in hundreds of cells. 
A

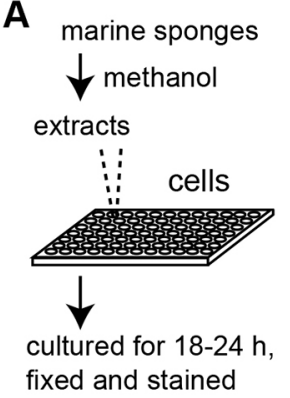

B

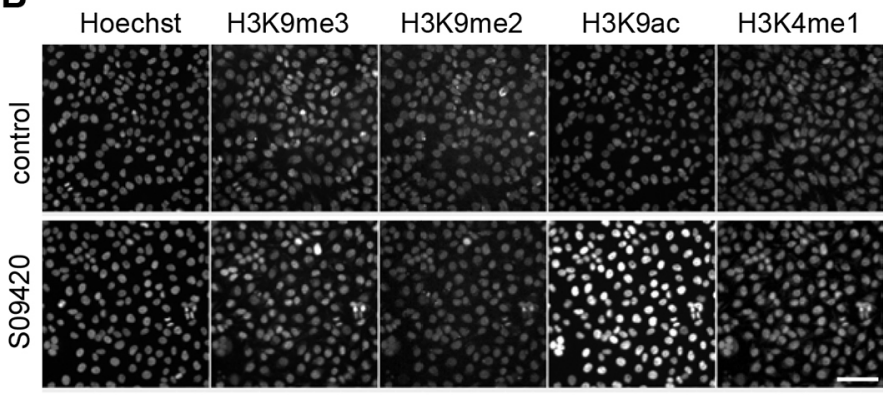

D
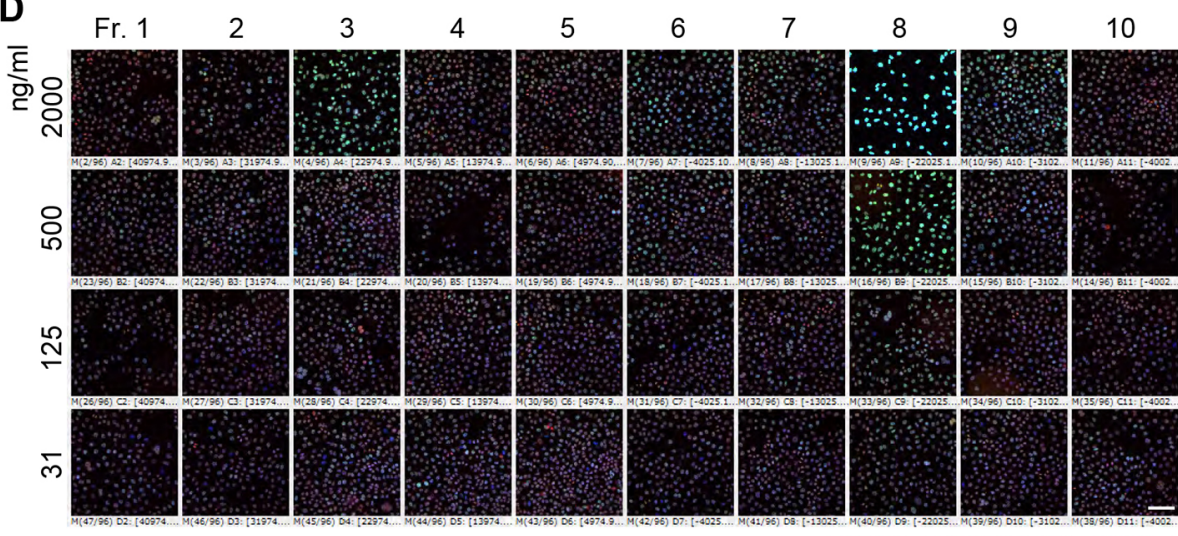

$\mathrm{H} 3 \mathrm{~K} 9 \mathrm{ac} / \mathrm{H} 3 \mathrm{~K} 9 \mathrm{me} / \mathrm{H} 3 \mathrm{~K} 27 \mathrm{ac}$
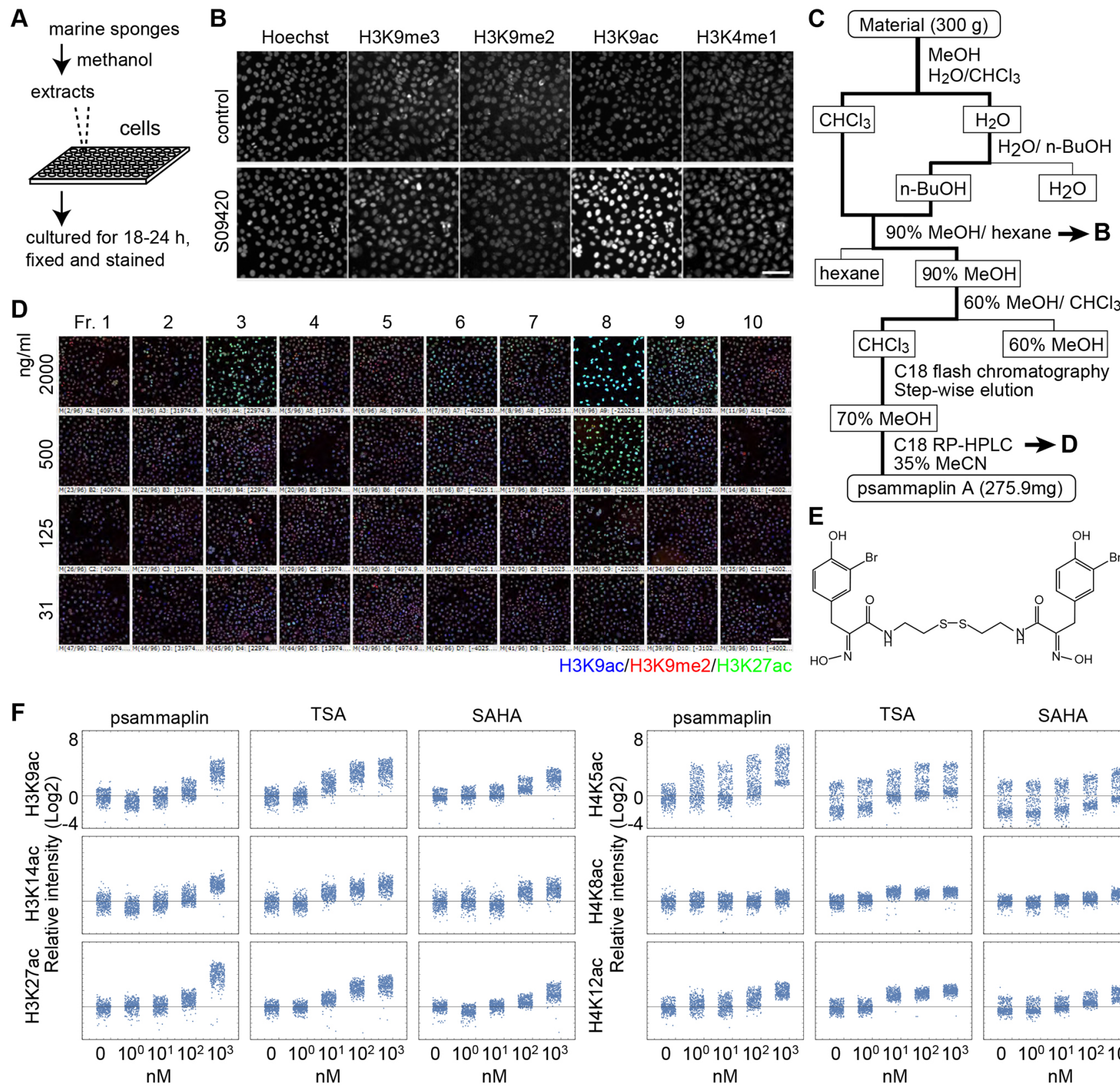

$60 \% \mathrm{MeOH} / \mathrm{CHCl}_{3}$
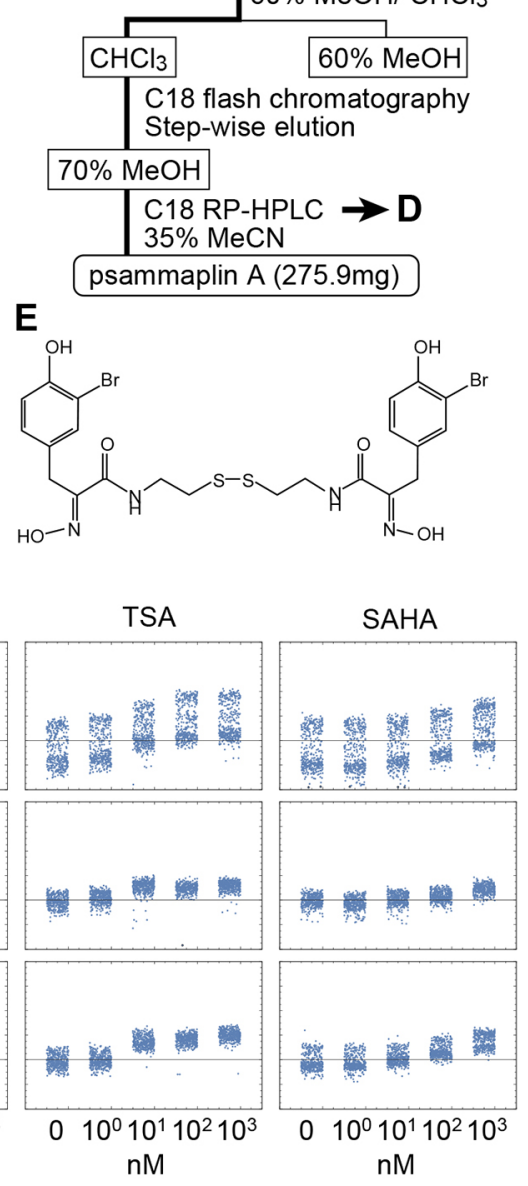

Fig. 7. Determination of HDAC activity in marine organism extracts. (A) Scheme used for the screening of substances affecting histone modifications. (B) Initial screening using a cell-based assay. The fraction of the sponge Aplysilla sp. (S09420) increased the levels of H3K9ac marks. (C) Scheme used for the purification of psammaplin A from the marine sponge. (D) Assays using the dilution series of each fraction. (E) The structural formula of psammaplin A. (F) Effect of HDAC inhibitors, psammaplin A, TSA and SAHA on the levels of histone acetylation. The levels of H3K9, H3K14, H3K27, H4K5, H4K8 and H4K12 were investigated using tenfold serial dilutions. Cell numbers: 400 . Scale bars: $100 \mu \mathrm{m}$.

We have shown that the assay system for quantifying histone modification levels is considerably robust. First, various antibody concentrations in the range of $0.25-4 \mu \mathrm{g} / \mathrm{ml}$ did not affect the quantitative results, suggesting that optimization of staining conditions may not be crucial. Second, effects of antibody steric hindrance were not observed in the antibody combinations tested, assuring reliability of the multiplex analysis. In principle, further multiplexing is possible using sophisticated fluorescence microscopy techniques such as linear unmixing (Tsurui et al., 2000; Garbacik et al., 2018) and fluorescence lifetime imaging (Niehörster et al., 2016). Furthermore, multiplexed antibody staining could be used in mass cytometry imaging (Chang et al.,
2017) to detect tens of different histone modifications simultaneously if the antibodies used remain functional after conjugation with metal-chelating polymers. In these higher multiplex systems, steric hindrance by many antibodies on chromatin could become problematic and so careful control experiments should be considered. Third, subtle fluctuations of nuclear focal planes among cells did not significantly affect the quantitative results when using a low NA objective lens. The cells used in this study were monolayers at subconfluent conditions and their nuclear focal planes were not significantly altered. Once the focus is set using the autofocus system, many nuclei in multiple fields are within the focus, and a range of objective lenses with NA 
0.75-1.25 could be used for quantitative analysis. We used a NA $0.9540 \times$ dry objective lens for most experiments in this study because dry lenses are convenient to use and the optical resolution and tolerance to focal shifts were adequate. For imaging at a higher resolution with quantitative analysis, a higher NA water-immersion lens can be used, but not a NA $1.4100 \times$ oil immersion lens. For cells with relatively large variation in the focal plane, using an NA 0.75 $20 \times$ dry objective lens may be more appropriate because the quantitative data for $2.4 \mu \mathrm{m}$ out-of-focus images are almost the same as those of in-focus images. In the single-plane imaging used in this study, however, the analysis of mitotic cells is not straightforward because the focal planes of condensed chromosomes are different from those of interphase nuclei. Moreover, mitotic phosphorylation near the methylation or acetylation site interferes with the binding of many modificationspecific antibodies.

We used an assay system to analyze changes in histone modifications during the cell cycle in response to KDM overexpression and inhibitor screening. The results of cell cycle dynamics and KDM target analyses were consistent with previous observations, thus confirming the validity of this method. Chemical screening, which resulted in the isolation of a known compound, also provided a proof of principle, suggesting that this method could be used for large-scale screening. Using manual handling, several 96-well plates could be processed within a few days; thus, analysis using an automated handling system would be more rapid and allow high throughput. This kind of application is particularly important because a chemical that regulates the epigenome could potentially serve as a drug target.

In this study, we analyzed histone modification dynamics using multicolor immunofluorescence-based single cell analysis. The experimental setup and quantitative analysis are not limited to histone modifications but can also be used for any nuclear proteins, such as HaloTag-tagged KDMs. Thus, this analytical system will be useful for future studies on nuclear protein and modification dynamics in response to stimuli and during the cell cycle.

\section{MATERIALS AND METHODS}

Generation, selection and purification of monoclonal antibodies

To generate monoclonal antibodies directed against H3K9un, H3K27un, $\mathrm{H} 3 \mathrm{~K} 27 \mathrm{me} 1$ and $\mathrm{H} 3 \mathrm{~K} 27 \mathrm{me}$, mice were immunized with synthetic peptides (H3K9un, ARTKQTARKSTGGKAPRKC; H3K27un, KQLATKAARKSAPATGGVKC; H3K27me1, KQLATKAAR(me1-K)SAPATGGVKC; and H3K27me2, KQLATKAAR(me2-K)SAPATGGVKC) coupled to the keyhole limpet hemocyanin, as described previously (Hayashi-Takanaka et al., 2015; Kimura et al., 2008). After generating hybridomas, clones were screened by enzyme-linked immunosorbent assay (ELISA) using the above-mentioned and following peptides: H3K9me1, ARTKQTAR(me1K)STGGKAPRKC; H3K9me2, ARTKQTAR(me2-K)STGGKAPRKC; H3K9me3, ARTKQTAR(me3-K)STGGKAPRKC; H3K9ac, ARTKQTAR(ac-K)STGGKAPRKC; H3K27me3, KQLATKAAR(me3-K)SAPATGGVKC; and H3K27ac, KQLATKAAR(ac-K)SAPATGGVKC. The specificity of the selected clones was validated by ELISA and MODified Histone Peptide Array (Active Motif) (Fig. S3).

To conduct experiments using mice, all institutional and national guidelines for the care and use of laboratory animals were followed. All animal care and experimental procedures in this study were approved by the Hokkaido University Animal Experiment Committee (approval number 11-0109) and carried out according to the guidelines for animal experimentation at Hokkaido University, which houses the Mab Institute Inc. Animals were housed in a specific pathogen-free facility at Hokkaido University. Humane euthanasia of mice was performed by cervical dislocation by skilled personnel with a high degree of technical proficiency.
Antibodies against other histone modifications used in this study have been described previously (Hayashi-Takanaka et al., 2009, 2011, 2015; Kimura et al., 2008; Rechtsteiner et al., 2010). Antibody purification and fluorescence labeling were performed as described previously (HayashiTakanaka et al., 2011, 2014). Rabbit anti-HaloTag antibody (G9218) was purchased from Promega, and donkey anti-rabbit IgG (minimal crossreaction to bovine, chicken, goat, guinea pig, Syrian hamster, horse, human, mouse, rat and sheep serum proteins; 711-005-152) was purchased from Jackson ImmunoResearch. To label anti-rabbit IgG with Alexa Fluor 750, $100 \mu \mathrm{g}$ of anti-rabbit IgG was incubated with $8 \mu \mathrm{g}$ of Alexa Fluor $750 \mathrm{~N}$ succinimidyl ester (Thermo Fisher Scientific) in $100 \mathrm{mM} \mathrm{NaHCO}_{3}$ (pH 8.3) in a $100 \mu \mathrm{l}$ reaction volume for $1 \mathrm{~h}$ with rotation using a rotator (Titec RT$60 ; 10 \mathrm{~cm}$ radius; $\sim 10 \mathrm{rpm}$ ). The labeled antibody was separated from free Alexa Fluor 750 using a PD-mini G-25 desalting column (GE Healthcare) pre-equilibrated with PBS (Takara). After addition of the reaction mixture $(100 \mu 1)$ on to the column resin, $0.45 \mathrm{ml}$ of PBS was added and the flowthrough discarded. The Alexa Fluor 750-conjugated antibody was eluted using $0.5 \mathrm{ml}$ of PBS and concentrated up to $\sim 1 \mathrm{mg} / \mathrm{ml}$ using an Ultrafree 0.5 filter (10 k-cut off; Millipore).

\section{Cell culture}

HeLa and hTERT-RPE1 cells have been described previously (HayashiTakanaka et al., 2015; Hayashi-Takanaka et al., 2019); 293 T cells were obtained from Dr Kei Fujinaga (Sapporo Medical School) in 1991. Cells were grown in Dulbecco's modified Eagle's medium, high glucose (Nacalai Tesque) supplemented with glutamine $(2 \mathrm{mM})$, penicillin $(100 \mathrm{U} / \mathrm{ml})$, streptomycin $(100 \mu \mathrm{g} / \mathrm{ml}$; Sigma-Aldrich) and $10 \%$ fetal calf serum (Gibco; Thermo Fisher Scientific).

\section{Immunofluorescence and microscopy}

Cells were plated in a 12-well plate containing a coverslip (15 mm diameter; no. 1S; Matsunami). After more than $24 \mathrm{~h}$ of culture, the cells were fixed for 5 min with $4 \%$ paraformaldehyde in $250 \mathrm{mM}$ HEPES ( $\mathrm{pH} 7.4$ ) containing $0.1 \%$ Triton X-100, permeabilized with $1 \%$ Triton X-100 in PBS for $20 \mathrm{~min}$ and blocked with Blocking One-P (Nacalai Tesque) for $15 \mathrm{~min}$, as described previously (Kimura et al., 2008). The fixed cells were then incubated with labeled antibodies $(0.2-1 \mu \mathrm{g} / \mathrm{ml})$ and $0.1 \mu \mathrm{g} / \mathrm{ml}$ of Hoechst 33342 for $2 \mathrm{~h}$ at room temperature, and then washed three times with PBS for a total of $30 \mathrm{~min}$. The cells in Fig. S2A were treated with $500 \mu \mathrm{l}$ RNase A $(100 \mu \mathrm{g} / \mathrm{ml}$ in PBS; Nacalai Tesque) overnight at $4{ }^{\circ} \mathrm{C}$, washed with PBS and incubated with $50 \mu \mathrm{l}$ propidium iodide $(20 \mu \mathrm{g} / \mathrm{ml}$; Sigma-Aldrich) and labeled antibodies in PBS for $2 \mathrm{~h}$. Coverslips were mounted on glass slides in Prolong Gold (Thermo Fisher Scientific) (Kimura et al., 2008). Fluorescence images were collected using a Ti-E inverted microscope (Nikon), under the operation of NIS Elements version 3.0 (Nikon), with a PlanApo VC or Lambda $40 \times$ dry (NA 0.95) objective lens equipped with an electron-multiplying charge-coupled device (EM-CCD; iXon+; Andor; normal mode; gain $\times 5.1$ ) with filter sets (DAPI-1160A for Hoechst 33342 , LF488-A for Alexa Fluor 488, LF561-A for Cy3, Cy5-4040A for Cy5, and FF01-732/68, FF757-Di01, FF01-776/LP for Alexa Fluor 750; Semrock). The exposure period was set at $100-1000 \mathrm{~ms}$ using a $75 \mathrm{~W}$ Xenon lamp as light source. Multipoint images were collected using a motorized X-Y stage with an autofocus system to retain a constant offset distance from the surface of the coverslip (Nikon Ti-E). The images in Fig. 2B and Fig. 3 were collected using PlanApo VC $20 \times$ dry (NA 0.75), Apo Lambda S $40 \times$ waterimmersion (NA 1.25), PlanApo 60× water-immersion (NA 1.20), and PlanApo VC 100× oil-immersion (NA 1.4) objective lenses.

To identify cells in the $\mathrm{S}$ phase, cells were incubated in $10 \mu \mathrm{M}$ EdU (Thermo Fisher Scientific) for $7.5 \mathrm{~min}$ and then fixed in $4 \%$ paraformaldehyde dissolved in $250 \mathrm{mM}$ HEPES and $0.1 \%$ Triton X-100. The signal was detected using a Click-iT EdU Imaging Kit with Alexa Fluor 647 azide (Thermo Fisher Scientific).

\section{Image analysis}

Fluorescence intensities of nuclei were measured using NIS Elements version 3.0 (Nikon). Background intensity outside the cells was subtracted from the images, and the area of nuclei in individual cells was determined using an automatic threshold of Hoechst signals. After visual inspection to 
fine-tune the threshold level in a single field (as shown in Fig. 1C), the same setting was applied to all other fields in the same sample. Proper nuclear segmentation was confirmed by visual inspection. A nuclear doublet was often segmented as a single nuclear area; in this case, each nucleus was separated using the 'Separate objects manually' tool in NIS Elements. Nuclei exhibiting abnormal shape and intensity, like those in apoptotic cells, were manually omitted using the 'Delete object' tool. The total intensity (average intensity $\times$ nuclear area) of each nucleus was measured for all fluorescence channels. When multiple fields are imaged using the autofocus system in a small area (within a few millimeters), both the background and signal intensities were similar enough among the images in different fields that no normalization was required for multipoint images in the same sample. To quantify approximately 500 cells, it takes approximately 10 40 min to segment nuclei in 25-35 fields with a $40 \times$ objective lens using a semi-manual system. Cells in the M phase were not included in this analysis because the area of mitotic condensed chromosomes differed substantially from that of interphase nuclei.

For plotting the intensity distribution, the Hoechst signal intensity in each nucleus was normalized using the fifth lowest and fifth highest intensity nuclei set as 1 and 2, respectively (because the lowest and highest intensity nuclei were sometimes outliers). For histone modification, the intensity in each nucleus was normalized using the average. The normalized intensities were plotted on a linear scale for cell cycle analysis and on a log scale for perturbation assays, such as KDM expression and HDAC inhibitor treatments, using Mathematica version 9-11 (Wolfram Research). The source data and Mathematica code for making plots and heatmaps (Fig. 1D-F) are available at https://github.com/YTHayashi/SingleCellAnalysis.

\section{Flow cytometry}

HeLa cells grown on a $10 \mathrm{~cm}$ dish $\left(2.4 \times 10^{6}\right)$ were trypsinized, collected via centrifugation (1300 $\times \mathrm{g}$ for $3 \mathrm{~min}$ ), and resuspended in $300 \mu \mathrm{l}$ of PBS. The cells were fixed by adding and mixing with $700 \mu \mathrm{l}$ of $100 \%$ ethanol, resulting in a $70 \%$ ethanol solution, and stored for $1 \mathrm{~h}$ at $-20^{\circ} \mathrm{C}$. After centrifugation $\left(1300 \times \mathrm{g}\right.$ for $3 \mathrm{~min}$ at $\left.4^{\circ} \mathrm{C}\right)$, the $70 \%$ ethanol was discarded and the cells resuspended in $1 \mathrm{ml}$ of PBS. The cells were then washed twice with PBS and incubated in $0.5 \mathrm{ml}$ Blocking One-P (Nacalai Tesque) for $15 \mathrm{~min}$. Subsequently, the cells were incubated with three labeled antibodies $(0.2-1 \mu \mathrm{g} / \mathrm{ml})$ and Hoechst $33342(0.1 \mu \mathrm{g} / \mathrm{ml})$ in a $500 \mu 1$ reaction mixture for $2 \mathrm{~h}$ at room temperature. After washing with PBS, the cells were analyzed using a FACSAria IIIu (BD Biosciences) featuring 375, 488, 561 and $633 \mathrm{~nm}$ lasers. The cells stained with single antibodies and Hoechst 33342 were used to adjust the compensation parameters.

\section{HaloTag-KDM expression}

The following Kazusa cDNA clones were used to express the HaloTagKDM expression vectors: KDM1A (FHC 00571), KDM2A (FHC 00712), KDM3A (FHC 01605), KDM3B (FHC 05559), KDM3C (FHC36094E), KDM4A (FHC00602), KDM4B (FHC00669), KDM4C (FHC00635), KDM4D (FHC06842), KDM5A (FHC01704), KDM5B (FHC27753), KDM5C (FHC11536), KDM5D (FHC00039) and KDM6B (FHC00327). To conduct transient expression assays, 293T cells were plated in a 12-well plate containing a coverslip in each well, as described above, at $20-30 \%$ confluency. On the next day, transfection was performed using GeneJuice transfection reagent (Merck), according to the manufacturer's instructions; briefly, $0.5 \mu \mathrm{g}$ of DNA was mixed with $50 \mu \mathrm{l}$ of Opti-MEM (Thermo Fisher Scientific) and then $1.5 \mu \mathrm{l}$ of GeneJuice Reagent was added to the mixture. Approximately $24 \mathrm{~h}$ after transfection, the cells were fixed, permeabilized and blocked, as described above. Cells were stained with rabbit antiHaloTag antibody (1:1000) for $2 \mathrm{~h}$ and then with Alexa Fluor 750-labeled anti-rabbit IgG $(2 \mu \mathrm{g} / \mathrm{ml}$; secondary antibody), dye-labeled histone modification-specific antibodies and Hoechst 33342 at room temperature.

\section{Determination of HDAC inhibitory activity in marine organism extract}

To screen chemicals that affect histone modification levels, MDA-MB-231 cells were cultured in 96-well glass-bottom plates (AGC techno glass) in DMEM containing $10 \mu \mathrm{g} / \mathrm{ml}$ extracts $\left(2 \times 10^{3}\right.$ to $4 \times 10^{3}$ cells in $100 \mu \mathrm{l}$ medium in each well), incubated in a $\mathrm{CO}_{2}$ incubator for 18-24 h, and fixed and stained as described above. To examine the effect of HDAC inhibitors on histone acetylation levels, cells were incubated for $4 \mathrm{~h}$ in the presence of inhibitors prior to fixation. Fluorescence images of individual wells were collected using an inverted microscope (Ti-E; Nikon) equipped with an X-Y stage (Nikon), using a PlanApo $20 \times$ dry objective lens (NA 0.75).

The marine sponge sample (S09420) that enhanced the levels of H3K9ac and H3K27ac was extracted from a sponge identified as Aplysilla sp., which was collected from Pisira Island, Chuuk, Federated States of Micronesia $\left(7^{\circ} 29.04^{\prime} \mathrm{N}, \mathrm{E} 151^{\circ} 49.69^{\prime} \mathrm{E}\right)$ in September 2009. The material was stored at $-30^{\circ} \mathrm{C}$ until required for analysis. The frozen material $(300 \mathrm{~g})$ was extracted five times with methanol $(1000 \mathrm{ml})$ at room temperature. The crude extract was concentrated and partitioned into aqueous and chloroform layers. The aqueous layer was extracted with 1-butanol and combined with the chloroform layer. The organic layer was subjected to a modified Kupchan method (Kupchan et al., 1973) yielding 1-hexane, chloroform and aqueous methanol layers. The chloroform layer was applied to ODS flash chromatography (ODS-A 120-S150; YMC) and the column was eluted in a stepwise manner with methanol:water (5:5 and 7:3), acetonitrile:water (7:3 and 17:3), methanol and chloroform:methanol:water (6:4:1). The methanol: water (7:3) fraction, which contained the activity to increase $\mathrm{H} 3 \mathrm{~K} 9 \mathrm{ac}$ and $\mathrm{H} 3 \mathrm{~K} 27 \mathrm{ac}$ levels, was further separated by reversed-phase HPLC (COSMOSIL $5 \mathrm{C}_{18}$ AR-II) in $40 \%$ acetonitrile to yield pure psammaplin $A$ as the active substance $(255 \mathrm{mg})$. The structure of psammaplin A was identified by comparison of the NMR spectra and MS data with a previous study (Arabshahi and Schmitz, 1987).

\section{Acknowledgements}

We thank Mr Kind Kanemoto Kanto from the College of Micronesia for his help in the collection of the sponge sample. We also thank Dr Timothy J. Stasevich (Colorado State University) for instruction in the use of Mathematica. The flow cytometry analysis was supported by Dr Hiroshi Yamazaki and the Center for Medical Research and Education, Graduate School of Medicine, Osaka University.

\section{Competing interests}

N.N. is a founder of Mab Institute Inc.

\section{Author contributions}

Conceptualization: Y.H., H.K.; Methodology: Y.H., H.K.; Software: Y.H.; Validation: H.K.; Formal analysis: Y.H.; Investigation: Y.H., Y.K., F.N.; Resources: L.E.B., Y.N. T.N., N.N., H.K.; Writing - original draft: Y.H., H.K.; Writing - review \& editing: Y.N.; Supervision: Y.N., H.K.; Funding acquisition: Y.H., Y.N., H.K.

\section{Funding}

This work was supported by grants-in-aid from Japan Society for the Promotion of Science (JSPS; JP25116005, JP26291071, JP17H01417 and JP18H05527 to H.K.; and JP21404010, JP25560408, JP26221204, and JP18H02100 to Y.N.), Japan Science and Technology Corporation (JST-CREST; JPMJCR16G1), and Japan Agency for Medical Research and Development (AMED-BINDS;

JP19am0101105) to H.K., and the Naito Foundation and the Urakami Foundation to Y.H.-T. Deposited in PMC for immediate release.

\section{Supplementary information}

Supplementary information available online at

https://jcs.biologists.org/lookup/doi/10.1242/jcs.243444.supplemental

\section{Peer review history}

The peer review history is available online at

https://jcs.biologists.org/lookup/doi/10.1242/jcs.243444.reviewer-comments.pdf

\section{References}

Agger, K., Cloos, P. A. C., Christensen, J., Pasini, D., Rose, S., Rappsilber, J., Issaeva, I., Canaani, E., Salcini, A. E. and Helin, K. (2007). UTX and JMJD3 are histone $\mathrm{H} 3 \mathrm{~K} 27$ demethylases involved in $\mathrm{HOX}$ gene regulation and development. Nature 449, 731-734. doi:10.1038/nature06145

Alabert, C., Barth, T. K., Reverón-Gómez, N., Sidoli, S., Schmidt, A., Jensen, O. N. and Imhof, A. (2015). Two distinct modes for propagation of histone PTMs across the cell cycle. Genes Dev. 29, 585-590. doi:10.1101/gad.256354.114

Allis, C. D., Chicoine, L. G., Richman, R. and Schulman, I. G. (1985). Depositionrelated histone acetylation in micronuclei of conjugating Tetrahymena. Proc. Nat/. Acad. Sci. USA 82, 8048-8052. doi:10.1073/pnas.82.23.8048

Arabshahi, L. and Schmitz, F. J. (1987). Brominated tyrosine metabolites from an unidentified sponge. J. Org. Chem. 52, 3584-3586. doi:10.1021/jo00392a016 
Bar-Ziv, R., Voichek, Y. and Barkai, N. (2016). Chromatin dynamics during DNA replication. Genome Res. 26, 1245-1256. doi:10.1101/gr.201244.115

Bernstein, B. E., Kamal, M., Lindblad-Toh, K., Bekiranov, S., Bailey, D. K. Huebert, D. J., McMahon, S., Karlsson, E. K., Kulbokas, E. J., Gingeras, T. R. et al. (2005). Genomic maps and comparative analysis of histone modifications in human and mouse. Cell 120,169-181. doi:10.1016/j.cell.2005.01.001

Black, J. C., van Rechem, C. and Whetstine, J. R. (2012). Histone lysine methylation dynamics: establishment, regulation, and biological impact. Mol. Cell 48, 491-507. doi:10.1016/j.molcel.2012.11.006

Chahal, S. S., Matthews, H. R. and Bradbury, E. M. (1980). Acetylation of histone $\mathrm{H} 4$ and its role in chromatin structure and function. Nature 287, 76-79. doi:10. 1038/287076a0

Chandra, T., Kirschner, K., Thuret, J.-Y., Pope, B. D., Ryba, T., Newman, S. Ahmed, K., Samarajiwa, S. A., Salama, R., Carroll, T. et al. (2012). Independence of repressive histone marks and chromatin compaction during senescent heterochromatic layer formation. Mol. Cell 47, 203-214. doi:10.1016/j. molcel.2012.06.010

Chang, Q., Ornatsky, O. I., Siddiqui, I., Loboda, A., Baranov, V. I. and Hedley, D. W. (2017). Imaging mass cytometry. Cytometry A 91, 160-169. doi:10.1002/ cyto.a.23053

Chicoine, L. G., Schulman, I. G., Richman, R., Cook, R. G. and Allis, C. D. (1986) Nonrandom utilization of acetylation sites in histones isolated from Tetrahymena. Evidence for functionally distinct $\mathrm{H} 4$ acetylation sites. J. Biol. Chem. 261 1071-1076

Christensen, J., Agger, K., Cloos, P. A. C., Pasini, D., Rose, S., Sennels, L., Rappsilber, J., Hansen, K. H., Salcini, A. E. and Helin, K. (2007). RBP2 belongs to a family of demethylases, specific for tri- and dimethylated lysine 4 on histone 3. Cell 128, 1063-1076. doi:10.1016/j.cell.2007.02.003

Clancy, K. W., Russell, A.-M., Subramanian, V., Nguyen, H., Qian, Y., Campbell, R. M. and Thompson, P. R. (2017). Citrullination/methylation crosstalk on histone H3 regulates ER-target gene transcription. ACS Chem. Biol. 12, 1691-1702. doi:10.1021/acschembio.7b00241

Dang, W., Steffen, K. K., Perry, R., Dorsey, J. A., Johnson, F. B., Shilatifard, A. Kaeberlein, M., Kennedy, B. K. and Berger, S. L. (2009). Histone H4 lysine 16 acetylation regulates cellular lifespan. Nature 459, 802-807. doi:10.1038/ nature 08085

Fukuda, M., Sakaue-Sawano, A., Shimura, C., Tachibana, M., Miyawaki, A. and Shinkai, Y. (2019). G9a-dependent histone methylation can be induced in G1 phase of cell cycle. Sci. Rep. 9, 956. doi:10.1038/s41598-018-37507-5

Garbacik, E. T., Sanz-Paz, M., Borgman, K. J. E., Campelo, F. and GarciaParajo, M. F. (2018). Frequency-encoded multicolor fluorescence imaging with single-photon-counting color-blind detection. Biophys. J. 115, 725-736. doi:10. 1016/j.bpj.2018.07.008

Greer, E. L. and Shi, Y. (2012). Histone methylation: A dynamic mark in health disease and inheritance. Nat. Rev. Genet. 13, 343-357. doi:10.1038/nrg3173

Guertin, M. J., Zhang, X., Anguish, L., Kim, S., Varticovski, L., Lis, J. T., Hager, G. L. and Coonrod, S. A. (2014). Targeted H3R26 deimination specifically facilitates estrogen receptor binding by modifying nucleosome structure. PLoS Genet. 10, e1004613. doi:10.1371/journal.pgen.1004613

Gurley, L. R., Walters, R. A. and Tobey, R. A. (1975). Sequential phosphorylation of histone subfractions in the Chinese hamster cell cycle. J. Biol. Chem. 250 3936-3944

Harutyunyan, A. S., Krug, B., Chen, H., Papillon-Cavanagh, S., Zeinieh, M., De Jay, N., Deshmukh, S., Chen, C. C. L., Belle, J., Mikael, L. G. et al. (2019) H3K27M induces defective chromatin spread of PRC2-mediated repressive H3K27me2/me3 and is essential for glioma tumorigenesis. Nat. Commun. 10 1262. doi:10.1038/s41467-019-09140-X

Hayashi-Takanaka, Y., Yamagata, K., Nozaki, N. and Kimura, H. (2009) Visualizing histone modifications in living cells: spatiotemporal dynamics of $\mathrm{H} 3$ phosphorylation during interphase. J. Cell Biol. 187, 781-790. doi:10.1083/jcb. 200904137

Hayashi-Takanaka, Y., Yamagata, K., Wakayama, T., Stasevich, T. J., Kainuma T., Tsurimoto, T., Tachibana, M., Shinkai, Y., Kurumizaka, H., Nozaki, N. et al. (2011). Tracking epigenetic histone modifications in single cells using Fab-based live endogenous modification labeling. Nucleic Acids Res. 39, 6475-6488. doi:10. 1093/nar/gkr343

Hayashi-Takanaka, Y., Stasevich, T. J., Kurumizaka, H., Nozaki, N. and Kimura, H. (2014). Evaluation of chemical fluorescent dyes as a protein conjugation partner for live cell imaging. PLoS ONE 9, e106271. doi:10.1371/journal.pone. 0106271

Hayashi-Takanaka, Y., Maehara, K., Harada, A., Umehara, T., Yokoyama, S., Obuse, C., Ohkawa, Y., Nozaki, N. and Kimura, H. (2015). Distribution of histone $\mathrm{H} 4$ modifications as revealed by a panel of specific monoclonal antibodies. Chromosome Res. 23, 753-766. doi:10.1007/s10577-015-9486-4

Hayashi-Takanaka, Y., Kina, Y., Nakamura, F., Yamazaki, S., Harata, M., van Soest, R. W. M., Kimura, H. and Nakao, Y. (2019). Effect of mycalolides isolated from a marine sponge Mycale aff. nullarosette on actin in living cells. Sci. Rep. $\mathbf{9}$, 7540. doi:10.1038/s41598-019-44036-2

Hillringhaus, L., Yue, W. W., Rose, N. R., Ng, S. S., Gileadi, C., Loenarz, C. Bello, S. H., Bray, J. E., Schofield, C. J. and Oppermann, U. (2011). Structural and evolutionary basis for the dual substrate selectivity of human KDM4 histone demethylase family. J. Biol. Chem. 286, 41616-41625. doi:10.1074/jbc.M111. 283689

Hong, S., Cho, Y.-W., Yu, L.-R., Yu, H., Veenstra, T. D. and Ge, K. (2007) Identification of JmjC domain-containing UTX and JMJD3 as histone H3 lysine 27 demethylases. Proc. Natl. Acad. Sci. USA 104, 18439-18444. doi:10.1073/pnas. 0707292104

Huang, H., Lin, S., Garcia, B. A. and Zhao, Y. (2015). Quantitative proteomic analysis of histone modifications. Chem. Rev. 115, 2376-2418. doi:10.1021/ cr500491u

Jasencakova, Z., Scharf, A. N. D., Ask, K., Corpet, A., Imhof, A., Almouzni, G. and Groth, A. (2010). Replication stress interferes with histone recycling and predeposition marking of new histones. Mol. Cell 37, 736-743. doi:10.1016/j. molcel.2010.01.033

Jenuwein, T. and Allis, D. C. (2001). Translating the histone code. Science 293 1074-1080. doi:10.1126/science.1063127

Jiang, Y., Ahn, E.-Y., Ryu, S. H., Kim, D.-K., Park, J.-S., Yoon, H. J., You, S., Lee, B.-J., Lee, D. S. and Jung, J. H. (2004). Cytotoxicity of psammaplin A from a twosponge association may correlate with the inhibition of DNA replication. BMC Cancer 4, 70. doi:10.1186/1471-2407-4-70

Kim, T. H., Barrera, L. O., Qu, C., van Calcar, S., Trinklein, N. D., Cooper, S. J. Luna, R. M., Glass, C. K., Rosenfeld, M. G., Myers, R. M. et al. (2005). Direct isolation and identification of promoters in the human genome. Genome Res. 15 830-839. doi:10.1101/gr.3430605

Kimura, H. (2013). Histone modifications for human epigenome analysis. J. Hum Genet. 58, 439-445. doi:10.1038/jhg.2013.66

Kimura, H., Hayashi-Takanaka, Y., Goto, Y., Takizawa, N. and Nozaki, N. (2008) The organization of histone $\mathrm{H} 3$ modifications as revealed by a panel of specific monoclonal antibodies. Cell Struct. Funct. 33, 61-73. doi:10.1247/csf.07035

Kouzarides, T. (2007). Chromatin modifications and their function. Cell 128 693-705. doi:10.1016/j.cell.2007.02.005

Kupchan, S. M., Britton, R. W., Ziegler, M. F. and Sioel, C. W. (1973). Bruceantin, a new potent antileukemic simaroubolide from Brucea antidysenterica. J. Org Chem. 38, 178-179. doi:10.1021/jo00941a049

Lan, F., Bayliss, P. E., Rinn, J. L., Whetstine, J. R., Wang, J. K., Chen, S., Iwase, S., Alpatov, R., Issaeva, I., Canaani, E. et al. (2007). A histone H3 lysine 27 demethylase regulates animal posterior development. Nature 449, 689-694. doi:10.1038/nature06192

Lawrence, M., Daujat, S. and Schneider, R. (2016). Lateral thinking: How histone modifications regulate gene expression. Trends Genet. 32, 42-56. doi:10.1016/j. tig.2015.10.007

Li, G., Sudlow, G. and Belmont, A. S. (1998). Interphase cell cycle dynamics of a late-replicating, heterochromatic homogeneously staining region: Precise choreography of condensation/decondensation and nuclear positioning. J. Cell Biol. 140, 975-989. doi:10.1083/jcb.140.5.975

Li, J., Ahn, J. H. and Wang, G. G. (2019). Understanding histone H3 lysine 36 methylation and its deregulation in disease. Cell Mol. Life Sci. 76, 2899-2916. doi:10.1007/s00018-019-03144-y

Lin, X., Huang, Y., Zou, Y., Chen, X. and Ma, X. (2016). Depletion of G9a gene induces cell apoptosis in human gastric carcinoma. Oncol. Rep. 35, 3041-3049. doi:10.3892/or.2016.4692

McBrian, M. A., Behbahan, I. S., Ferrari, R., Su, T., Huang, T.-W., Li, K., Hong C. S., Christofk, H. R., Vogelauer, M., Seligson, D. B. et al. (2013). Histone acetylation regulates intracellular $\mathrm{pH}$. Mol. Cell 49, 310-321. doi:10.1016/j.molcel. 2012.10.025

Niehörster, T., Löschberger, A., Gregor, I., Krämer, B., Rahn, H.-J., Patting, M., Koberling, F., Enderlein, J. and Sauer, M. (2016). Multi-target spectrally resolved fluorescence lifetime imaging microscopy. Nat. Methods 13, 257-262. doi:10.1038/nmeth.3740

Niu, Y., Desmarais, T. L., Tong, Z., Yao, Y. and Costa, M. (2015). Oxidative stress alters global histone modification and DNA methylation. Free Radic. Biol. Med. $\mathbf{8 2}$ 22-28. doi:10.1016/j.freeradbiomed.2015.01.028

Pesavento, J. J., Yang, H., Kelleher, N. L. and Mizzen, C. A. (2008). Certain and progressive methylation of histone $\mathrm{H} 4$ at lysine 20 during the cell cycle. Mol. Cell. Biol. 28, 468-486. doi:10.1128/MCB.01517-07

Petruk, S., Black, K. L., Kovermann, S. K., Brock, H. W. and Mazo, A. (2013) Stepwise histone modifications are mediated by multiple enzymes that rapidly associate with nascent DNA during replication. Nat. Commun. 4, 2841. doi:10. 1038/ncomms3841

Piña, I. C., Gautschi, J. T., Wang, G.-Y.-S., Sanders, M. L., Schmitz, F. J., France D., Cornell-Kennon, S., Sambucetti, L. C., Remiszewski, S. W., Perez, L. B. et al. (2003). Psammaplins from the sponge Pseudoceratina purpurea: Inhibition of both histone deacetylase and DNA methyltransferase. J. Org. Chem. 68 3866-3873. doi:10.1021/jo034248t

Quiñoà, E. and Crews, P. (1987). Phenolic constituents of psammaplysilla Tetrahedron Lett. 28, 3229-3232. doi:10.1016/S0040-4039(00)95478-9

Rechtsteiner, A., Ercan, S., Takasaki, T., Phippen, T. M., Egelhofer, T. A., Wang, W., Kimura, H., Lieb, J. D. and Strome, S. (2010). The Histone H3K36 methyltransferase MES-4 acts epigenetically to transmit the memory of germline 
gene expression to progeny. PLoS Genet. 6, e1001091. doi:10.1371/journal. pgen.1001091

Reverón-Gómez, N., González-Aguilera, C., Stewart-Morgan, K. R., Petryk, N. Flury, V., Graziano, S., Johansen, J. V., Jakobsen, J. S., Alabert, C. and Groth, A. (2018). Accurate recycling of parental histones reproduces the gistone Modification landscape during DNA replication. Mol. Cell 72, 239-249.e5. doi:10. 1016/j.molcel.2018.08.010

Rice, J. C., Nishioka, K., Sarma, K., Steward, R., Reinberg, D. and Allis, C. D. (2002). Mitotic-specific methylation of histone H4 Lys 20 follows increased PRSet7 expression and its localization to mitotic chromosomes. Genes Dev. 16 2225-2230. doi:10.1101/gad.1014902

Rodriguez, A. D., Akee, R. K. and Scheuer, P. J. (1987). Two bromotyrosinecysteine derived metabolites from a sponge. Tetrahedron Lett. 28, 4989-4992. doi:10.1016/S0040-4039(00)96677-2

Roh, T.-Y., Cuddapah, S. and Zhao, K. (2005). Active chromatin domains are defined by acetylation islands revealed by genome-wide mapping. Genes Dev. 19, 542-552. doi:10.1101/gad.1272505

Sato, Y., Kujirai, T., Arai, R., Asakawa, H., Ohtsuki, C., Horikoshi, N., Yamagata K., Ueda, J., Nagase, T., Haraguchi, T. et al. (2016). A genetically encoded probe for live-cell imaging of H4K20 monomethylation. J. Mol. Biol. 428 3885-3902. doi:10.1016/j.jmb.2016.08.010

Shmakova, A., Batie, M., Druker, J. and Rocha, S. (2014). Chromatin and oxygen sensing in the context of JmjC histone demethylases. Biochem. J. 462, 385-395. doi:10.1042/BJ20140754

Smith, C. M., Gafken, P. R., Zhang, Z., Gottschling, D. E., Smith, J. B. and Smith, D. L. (2003). Mass spectrometric quantification of acetylation at specific lysines within the amino-terminal tail of histone H4. Anal. Biochem. 316, 23-33. doi:10. 1016/S0003-2697(03)00032-0

Sobel, R. E., Cook, R. G., Perry, C. A., Annunziato, A. T. and Allis, C. D. (1995) Conservation of deposition-related acetylation sites in newly synthesized histones H3 and H4. Proc. Natl. Acad. Sci. USA 92, 1237-1241. doi:10.1073/pnas.92.4. 1237

Tabudravu, J. N., Eijsink, V. G. H., Gooday, G. W., Jaspars, M., Komander, D., Legg, M., Synstad, B. and van Aalten, D. M. F. (2002). Psammaplin A, a chitinase inhibitor isolated from the fijian marine sponge aplysinella rhax. Bioorg. Med. Chem. 10, 1123-1128. doi:10.1016/S0968-0896(01)00372-8
Tsukada, Y.-I., Fang, J., Erdjument-Bromage, H., Warren, M. E., Borchers, C. H., Tempst, P. and Zhang, Y. (2006). Histone demethylation by a family of JmjC domain-containing proteins. Nature 439, 811-816. doi:10.1038/nature04433

Tsurui, H., Nishimura, H., Hattori, S., Hirose, S., Okumura, K. and Shirai, T. (2000). Seven-color fluorescence imaging of tissue samples based on Fourie spectroscopy and singular value decomposition. J. Histochem. Cytochem. 48, 653-662. doi:10.1177/002215540004800509

Xiang, Y., Zhu, Z., Han, G., Lin, H., Xu, L. and Chen, C. D. (2007). JMJD3 is a histone H3K27 demethylase. Cell Res. 17, 850-857. doi:10.1038/cr.2007.83

Xu, M., Wang, W., Chen, S. and Zhu, B. (2012). A model for mitotic inheritance of histone lysine methylation. EMBO Rep. 13, 60-67. doi:10.1038/embor.2011.206

Yamamoto, K., Chikaoka, Y., Hayashi, G., Sakamoto, R., Yamamoto, R., Sugiyama, A., Kodama, T., Okamoto, A. and Kawamura, T. (2015). Middledown and chemical proteomic approaches to reveal histone $\mathrm{H} 4$ modification dynamics in cell cycle. Mass Spectrom. 4, A0039. doi:10.5702/ massspectrometry.A0039

Yuan, W., Xu, M., Huang, C., Liu, N., Chen, S. and Zhu, B. (2011). H3K36 methylation antagonizes PRC2-mediated H3K27 methylation. J. Biol. Chem. 286 , 7983-7989. doi:10.1074/jbc.M110.194027

Zane, L., Chapus, F., Pegoraro, G. and Misteli, T. (2017). HiHiMap: single-cel quantitation of histones and histone posttranslational modifications across the cell cycle by high-throughput imaging. Mol. Biol. Cell 28, 2290-2302. doi:10.1091/ mbc.e16-12-0870

Zee, B. M., Levin, R. S., Dimaggio, P. A. and Garcia, B. A. (2010a). Global turnover of histone post-translational modifications and variants in human cells. Epigenet. Chromatin 3, 22. doi:10.1186/1756-8935-3-22

Zee, B. M., Levin, R. S., Xu, B., Leroy, G., Wingreen, N. S. and Garcia, B. A (2010b). In vivo residue-specific histone methylation dynamics. J. Biol. Chem. 285, 3341-3350. doi:10.1074/jbc.M109.063784

Zee, B. M., Britton, L.-M. P., Wolle, D., Haberman, D. M. and Garcia, B. A. (2012) Origins and formation of histone methylation across the human cell cycle. $\mathrm{Mol}$ Cell. Biol. 32, 2503-2514. doi:10.1128/MCB.06673-11

Zheng, Y., Huang, X. and Kelleher, N. L. (2016). Epiproteomics: quantitative analysis of histone marks and codes by mass spectrometry. Curr. Opin. Chem. Biol. 33, 142-150. doi:10.1016/j.cbpa.2016.06.007 